\title{
Carboxymethyl Hyaluronan-Stabilized Nanoparticles for Anticancer Drug Delivery
}

\author{
Jessica L. Woodman, ${ }^{1,2}$ Min Sung Suh, ${ }^{3}$ Jianxing Zhang, ${ }^{4}$ Yuvabharath Kondaveeti, \\ Diane J. Burgess, ${ }^{3}$ Bruce A. White, ${ }^{5}$ Glenn D. Prestwich, ${ }^{4}$ and Liisa T. Kuhn ${ }^{2}$ \\ ${ }^{1}$ Department of Materials Science and Engineering, University of Connecticut, Storrs, CT 06269, USA \\ ${ }^{2}$ Department of Reconstructive Sciences, UConn Health, Farmington, CT 06030, USA \\ ${ }^{3}$ Department of Pharmaceutical Sciences, University of Connecticut, Storrs, CT 06269, USA \\ ${ }^{4}$ Department of Medicinal Chemistry, University of Utah, Salt Lake City, UT 84108, USA \\ ${ }^{5}$ Department of Cell Biology, UConn Health, Farmington, CT 06030, USA
}

Correspondence should be addressed to Glenn D. Prestwich; glenn.prestwich@pharm.utah.edu

Received 26 September 2014; Accepted 31 March 2015

Academic Editor: Rony Seger

Copyright (C) 2015 Jessica L. Woodman et al. This is an open access article distributed under the Creative Commons Attribution License, which permits unrestricted use, distribution, and reproduction in any medium, provided the original work is properly cited.

Carboxymethyl hyaluronic acid (CMHA) is a semisynthetic derivative of HA that is recognized by HA binding proteins but contains an additional carboxylic acid on some of the 6-hydroxyl groups of the $\mathrm{N}$-acetyl glucosamine sugar units. These studies tested the ability of CMHA to stabilize the formation of calcium phosphate nanoparticles and evaluated their potential to target therapy resistant, $\mathrm{CD} 44^{+} / \mathrm{CD} 24^{-/ \text {low }}$ human breast cancer cells (BT-474 $\mathrm{EMT}_{\mathrm{T}}$ ). CMHA stabilized particles $\left(\mathrm{nCaP}^{\mathrm{CMHA}}\right.$ ) were loaded with the chemotherapy drug cis-diamminedichloroplatinum(II) (CDDP) to form nCaP ${ }^{\mathrm{CMHA}} \mathrm{CDDP}$. $\mathrm{nCaP} \mathrm{CMHA}^{\mathrm{CM}} \mathrm{CDDP}$ was determined to be poorly crystalline hydroxyapatite, $200 \mathrm{~nm}$ in diameter with a $-43 \mathrm{mV}$ zeta potential. $\mathrm{nCaP}{ }^{\mathrm{CMHA}} \mathrm{CDDP}$ exhibited a two-day burst release of CDDP that tapered resulting in $86 \%$ release by 7 days. Surface plasmon resonance showed that $n C a P{ }^{\mathrm{CMHA}} \mathrm{CDDP}$ binds to CD44, but less effectively than CMHA or hyaluronan. $\mathrm{nCaP}{ }^{\mathrm{CMHA}-\mathrm{AF} 488}$ was taken up by CD $44^{+} / \mathrm{CD} 24^{-} \mathrm{BT}-474_{\mathrm{EMT}}$ breast cancer cells within 18 hours. nCaP ${ }^{\mathrm{CMHA}} \mathrm{CDDP}$ was as cytotoxic as free CDDP against the BT-474 $4_{\mathrm{EMT}}$ cells. Subcutaneous BT- $474_{\mathrm{EMT}}$ tumors were more reproducibly inhibited by a near tumor dose of $2.8 \mathrm{mg} / \mathrm{kg}$ CDDP than a $7 \mathrm{mg} / \mathrm{kg}$ dose $\mathrm{nCaP}{ }^{\mathrm{CMHA}} \mathrm{CDDP}$. This was likely due to a lack of distribution of $\mathrm{nCaP}{ }^{\mathrm{CMHA}} \mathrm{CDDP}$ throughout the dense tumor tissue that limited drug diffusion.

\section{Introduction}

In the United States, over 1.6 million people were newly diagnosed with cancer in 2013 and 13.7 million people were battling cancer or were in remission [1]. Approximately 1 in 5 breast cancer survivors will have a recurrence within 10 years of adjuvant therapy [2]. While chemotherapies generally target rapidly dividing cells, relatively dormant cells exist within tumors which are resistant to chemotherapy [3-6]. Therapy-resistant breast cancer cells have a common phenotype of $\mathrm{CD} 44^{+} / \mathrm{CD} 24^{-/ \text {low }}$, in which $\mathrm{CD} 44$ is a transmembrane hyaluronan (HA) receptor. HA is a major glycosaminoglycan component of the extracellular matrix [7]. The expression of $\mathrm{CD} 44$ has been linked to cancer progression via metastases and drug resistance [8]. The presence of $\mathrm{CD} 44^{+}$cells in patients with triple negative breast cancer (TNBC) is an indicator of poor outcomes and is linked with recurrence [9]. TNBC patients have limited treatment options, because their cancer does not present with hormone receptors that are effectively targeted for treatment [10]. These patients could greatly benefit from a localized high dose treatment that could reduce the tumor size prior to surgical resection, thereby reducing the incidence of recurrence. Two histological studies examining breast cancer patient tumor samples prior to and after primary systemic chemotherapy evidenced an increase in therapy-resistant $\mathrm{CD} 44^{+} / \mathrm{CD} 24^{-/ \text {low }}$ cells after treatment $[5,11]$. The objective of this work was to determine whether calcium phosphate nanoparticles 
stabilized with a chemically modified HA could effectively target and kill therapy-resistant human TNBC cells with the $\mathrm{CD} 44^{+} / \mathrm{CD} 24^{\text {low }}$ phenotype.

Utilizing HA as a targeting moiety to deliver chemotherapeutics to cancer cells has been an ongoing area of research. One approach has been to chemically modify HA to allow attachment of carboxyl-containing drugs [12], and an HAPaclitaxel prodrug bioconjugate has been prepared that showed selective toxicity against cancer cells overexpressing CD44 $[13,14]$. Drug carrier systems modified with HA have been shown to enter the cell via CD44 mediated endocytosis [15]. Chen et al. showed mesoporous silica nanoparticles targeted with HA entered cells expressing CD44 [16]. In this study targeted calcium phosphate nanoparticles ( $\mathrm{nCaP}$ ) were synthesized as the drug carrier. Calcium phosphate is an excellent biomaterial because it is biocompatible, resorbable, and nonimmunogenic [17-19]. CaP synthesized via wet precipitation will form microcrystals, instead of nanoparticles, if crystallization and agglomeration are not halted with a stabilizer. Limiting crystal growth and agglomeration with a stabilizer is important to improve injectability of colloidal suspensions of $\mathrm{CaP}$ used for drug delivery. In the present studies, chemically modified HA was evaluated as a dual stabilizer/targeting ligand for $\mathrm{nCaP}$. The chemically modified HA had additional carboxylate groups installed on a predetermined fraction of the $\mathrm{N}$-acetylglucosamine units at the 6-hydroxyl group [20, 21]. Carboxylates interact with and stabilize calcium ions during precipitation of $\mathrm{CaP}$ [22]. The structure of the carboxymethyl hyaluronan (CMHA) used for these studies is shown in Figure 1.

It has been shown in our lab and others that stabilized $\mathrm{nCaP}$ can bind and release the chemotherapy drug cis-diamminedichloroplatinum (CDDP), a commonly used chemotherapeutic $[23,24]$. CDDP is an effective anticancer drug but has dose limiting nephrotoxicity; thus, improved formulations with less toxicity are needed. We hypothesized that CMHA could be used to stabilize $\mathrm{nCaP}$ and simultaneously target CD44 expressing therapy resistant cells while delivering CDDP. The $\mathrm{nCaP}{ }^{\mathrm{CMHA}} \mathrm{CDDP}$ was physically characterized using transmission electron microscopy (TEM), $\mathrm{X}$-ray diffraction, particle size analysis, and in vitro drug release studies. The ability of CMHA and $\mathrm{nCaP}{ }^{\mathrm{CMHA}} \mathrm{CDDP}$ to bind CD44 was examined using surface plasmon resonance. Cellular uptake was assessed using the $\mathrm{CD} 44^{+}$BT- $474_{\mathrm{EMT}}$ cells. Cytotoxicity of $\mathrm{nCaP}^{\mathrm{CMHA}} \mathrm{CDDP}$ and the impact of CMHA on cytotoxicity of Aq CDDP were examined in vitro against both CD44 ${ }^{-}$BT- 474 and $\mathrm{CD} 44^{+}$BT- $474_{\mathrm{EMT}}$ cell types. Lastly, an in vivo antitumor efficacy study was performedin a model of human therapy resistant TNBC using BT- $474_{\mathrm{EMT}}$ cells to create tumors in immunodeficient mice.

\section{Materials and Methods}

2.1. Materials. Calcium lactate pentahydrate (Sigma C8356), $\mathrm{K}_{2} \mathrm{HPO}_{4}$ (Sigma S1804), $\mathrm{Pt}\left(\mathrm{NH}_{3}\right) \mathrm{Cl}_{2}$ (CDDP, Sigma P4394), and $\mathrm{AgNO}_{3}$ (Silver Nitrate, Sigma S6506) used to prepare the nanoparticles were all purchased from Sigma-Aldrich, (St. Louis, MO). Darvan 811 was purchased from R. T. Vanderbilt
Holding Company, Inc. (Norwalk, CT). CMHA and HA for these studies were prepared as previously described $[20,21]$. Aquated CDDP (Aq CDDP) that does not contain chloride ions is a net positive charged molecule that can bind to calcium phosphate nanoparticles and was prepared as described previously [23]. As a control, Aq CDDP was reacted with a solution of CMHA overnight to form an electrostatically bound conjugate and used to investigate the cytotoxicity of CDDP and CMHA without the calcium phosphate phase present.

BT-474 $[25,26]$ and BT-474 $4_{\mathrm{EMT}}$ cells were used for the cytotoxicity testing and in vivo tumor studies. BT$474_{\text {EMT }}$ were derived from human HER2-amplified epithelial BT-474 through serial mammosphere cultures over three weeks as previously described [27]. Serial mammosphere culture caused the BT-474 cells to undergo EMT and generated cells with a mesenchymal phenotype including enhanced proliferation rate, and cell surface marker expression of $\mathrm{CD} 44^{+} / \mathrm{CD} 24^{-}$[28]. BT-474 cells were maintained in DMEM/F12 (Gibco 11330) with 10\% FBS, 1\% penicillin/streptomycin 10,000 U/mL (Gibco 15140), and 1\% insulin (Gibco 41400). BT-474 $\mathrm{EMT}$ cells were maintained in DMEM/F12 (Gibco 11330) with 10\% FBS, 1\% penicillin/streptomycin 10,000 U/mL (Gibco 15140). BD Matrigel for cell injections was purchased from BD Biosciences (San Jose, CA).

$\mathrm{J}: \mathrm{Nu}$ female mice were purchased from Jackson Laboratory (Bar Harbor, ME) and used for the in vivo tumor studies at 6-8 weeks of age. Female athymic nude mice, 6-8 weeks of age, were obtained from Charles River Laboratories International, Inc. (Wilmington, MA).

2.2. $n C a P{ }^{C M H A} C D D P$ Production and Physical Characterization. Synthesis of $\mathrm{nCaP}^{\mathrm{CMHA}} \mathrm{CDDP}$ was based on a previously reported method [23]. To make $\mathrm{nCaP}^{\mathrm{CMHA}}$, an equal volume of $30 \mathrm{mM} \mathrm{K} \mathrm{HPO}_{4}$ was added to stirred $30 \mathrm{mM}$ calcium lactate and immediately followed by addition of $2 \%$ $(\mathrm{w} / \mathrm{v})$ CMHA $(34 \mathrm{kDa})$ in water at $20 \%$ of the total volume of precipitation. Nanoparticles were collected after $10 \mathrm{~min}$ of mixing via centrifugation (12000 rpm for $45 \mathrm{~min}$ ) and washed once with MilliQ water. The $\mathrm{nCaP}^{\mathrm{CMHA}}$ was resuspended at a concentration of $4 \mathrm{mg}$ particles per $\mathrm{mL}$ of binding solution made of $1: 1(\mathrm{v}: \mathrm{v}) 20 \mathrm{mM}$ potassium phosphate buffer and $1 \mathrm{mg} / \mathrm{mL}$ Aq CDDP. After 20 hours of binding protected from light on a heated rocker (LAB-LINE thermorocker, Barnstead Thermolyne, Dubuque, IA) maintained at $37^{\circ} \mathrm{C}$, the particles were collected via centrifugation, rinsed with $10 \mathrm{mM} \mathrm{KPB}$, and diluted to approximately $175 \mathrm{mg} \mathrm{nCaP}{ }^{\mathrm{CMHA}} \mathrm{CDDP} / \mathrm{mL}$ MilliQ water. The suspension was injectable through a 25 gauge needle. All solutions/liquids during the synthesis process were sterile-filtered with a $0.2 \mu \mathrm{m}$ filter in order to prepare a sterile product for cell culture and animal testing. The $\mathrm{nCaP}^{\mathrm{CMHA}} \mathrm{CDDP}$ suspension was stored at room temperature and shielded from light prior to use. Another type of $\mathrm{nCaP}$ stabilized with Darvan $\left(\mathrm{nCaP}^{\mathrm{D}} \mathrm{CDDP}\right)$ instead of CMHA was made for use as a control for bulk shift during surface plasmon resonance studies. $\mathrm{nCaP}^{\mathrm{D}} \mathrm{CDDP}$ was prepared as previously described [23] except that calcium 


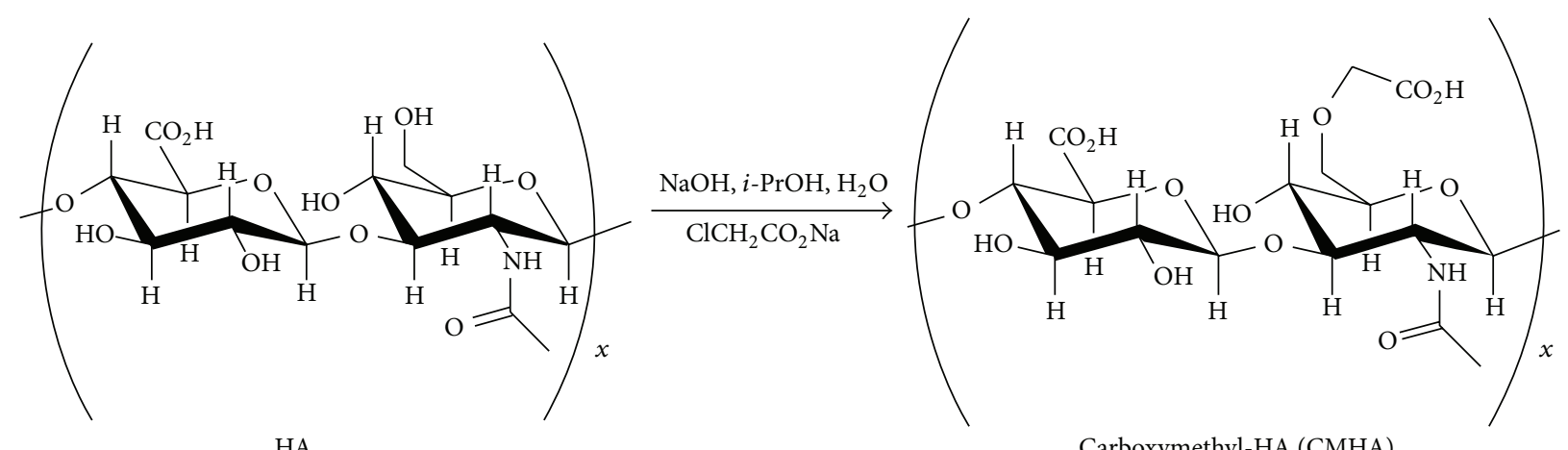

HA

Carboxymethyl-HA (CMHA)

FIGURE 1: Chemical modification of hyaluronan (HA) to carboxymethyl hyaluronan (CMHA). HA was chemically modified to produce CMHA in a basic solution which modifies approximately $15-20 \%$ of the $6^{\prime}-\mathrm{OH}$ groups of the $\mathrm{N}$-acetylglucosamine residues. This process reduces the molecular weight and introduces additional carboxyl groups for stabilization of $\mathrm{nCaP}$.

lactate pentahydrate was used instead of $\mathrm{Ca}\left(\mathrm{NO}_{3}\right)_{2} \cdot 4 \mathrm{H}_{2} \mathrm{O}$, to match the calcium used in $\mathrm{nCaP}{ }^{\mathrm{CMHA}} \mathrm{CDDP}$.

The concentration of CDDP within the $\mathrm{nCaP}{ }^{\mathrm{CMHA}} \mathrm{CDDP}$ and $\mathrm{nCaP}^{\mathrm{D}} \mathrm{CDDP}$ was determined by inductively coupled plasma-optical emission spectroscopy (ICP-OES) (Perkin Elmer Optima 5300 DV, ESIS Inc., Cromwell, CT) after dissolution of the particles in $1 \mathrm{~N} \mathrm{HCl}$. Particle size analysis (PSA) was performed via dynamic light scattering using a 90 Plus Particle Sizer (Brookhaven Instruments, NY). Samples were prepared by sonicating the particle suspension and diluting the suspension 12x in MilliQ water. The morphology and size of the particles were observed by using a Hitachi $\mathrm{H}$ 7650 transmission electron microscope (TEM). TEM samples were prepared by sonicating the particle suspension and diluting the suspension 26x in MilliQ water and then 10x in $70 \%$ ethanol prior to placing a $5 \mu \mathrm{L}$ sample on a formvar carbon coated 300 mesh Cu grid and blotting excess solution. Prior to imaging the sample was completely dried in air for $5 \mathrm{~min}$. Samples were imaged at $80 \mathrm{kV}$ with the TEM. $\mathrm{X}$-ray diffraction (XRD) was used to determine changes in crystallinity with addition of stabilizer and to compare dry versus wet $\mathrm{nCaP}$. Samples of lyophilized calcium phosphate without stabilizer (microCaP), lyophilized $\mathrm{nCaP}^{\mathrm{CMHA}}$, and wet $\mathrm{nCaP}{ }^{\mathrm{CMHA}}$ were analyzed using a Bruker D2 Phaser.

2.3. $n C a P{ }^{C M H A} C D D P$ In Vitro Drug Release. In vitro drug release studies were performed using a USP apparatus 4 (Sotax CE, Sotax, Horsham, PA) modified with a dialysis adapter with a molecular weight cut-off of $100 \mathrm{kD}$ [29]. A sample of $0.4 \mathrm{~mL}$ of particle suspension was loaded into the dialysis adapter with $100 \mu \mathrm{L}$ release medium. Release medium was $10 \mathrm{mM}$ PBS pH 7.4 with $0.1 \%$ sodium azide. A flow rate of $8 \mathrm{~mL} / \mathrm{min}$ was used for the study with the cell temperature maintained at $37^{\circ} \mathrm{C}$. Release samples were drawn at $1 \mathrm{~h}, 3 \mathrm{~h}$, $5 \mathrm{~h}, 7 \mathrm{hr}, 12 \mathrm{hr}, 1 \mathrm{~d}, 2 \mathrm{~d}, 3 \mathrm{~d}, 4 \mathrm{~d}, 5 \mathrm{~d}, 6 \mathrm{~d}, 7 \mathrm{~d}$, and $10 \mathrm{~d}$. At each time point $5 \mathrm{~mL}$ of release solution was taken and replaced with $5 \mathrm{~mL}$ of fresh PBS. CDDP content in the release solution was determined by ICP-OES. Media replacement during the release study was considered in the calculation of cumulative release.
2.4. Surface Plasmon Resonance. Interaction of $\mathrm{nCaP}^{\mathrm{CMHA}} \mathrm{CDDP}$, CMHA $(\sim 34 \mathrm{kDa})$, and $\mathrm{HA}(60 \mathrm{kDa})$ with $\mathrm{CD} 44$ were studied with surface plasmon resonance, BioRad ProteOn XPR36 with a GLC ProteOn sensor chip (BioRad, Hercules, CA). Recombinant human CD44-Fc chimera ( 170 kDa) (R\&D Systems, Minneapolis, MN) was immobilized on the sensor chip using amine coupling chemistry ProteOn Amine Coupling Kit. Briefly, the sensor chip surface was activated with 1:1 mixture of sulfo-N-hydroxysuccinimide (sulfo-NHS) and ethyl-3(3dimethylamino)propyl carbodiimide (EDC) for $7 \mathrm{~min}$. CD44-Fc was dissolved in $10 \mathrm{mM}$ acetate buffer $\mathrm{pH} 4$ to a concentration of $5 \mu \mathrm{g} / \mathrm{mL}$ and flown over the activated surface for $14 \mathrm{~min}$. The remaining reactive groups were blocked with $1 \mathrm{M}$ ethanolamine $\mathrm{HCl} \mathrm{pH}$ 8.5. A blank flow channel (FC) was prepared by EDC/NHS activation without the CD44 receptor. Throughout all the SPR measurements PBS pH 7.4 supplemented with $0.005 \%$ Tween 20 was used as the running buffer. Samples were diluted with running buffer. CMHA and HA were diluted to concentrations of $1 \mu \mathrm{M}$ and $5 \mu \mathrm{M} . \mathrm{nCaP}^{\mathrm{X}} \mathrm{CDDP}$ samples were diluted to a concentration of $350 \mu \mathrm{g} / \mathrm{mL}$, which was found to be a good compromise between sufficient binding response and bulk refractive index shift. The samples were injected over the sensor chip surface coated with human CD44-Fc at $100 \mu \mathrm{L} / \mathrm{min}$ for $150 \mathrm{~s}$. The dissociation in the running buffer took place for another 600 s. After each measurement cycle the sensor chip surface was regenerated with $10 \mathrm{mM}$ glycine $\mathrm{HCl} \mathrm{pH} 2.0$ at a flow rate of $200 \mu \mathrm{L} / \mathrm{min}$. The responses on the blank flow cell were subtracted from the CD44-Fc coated flow cell.

2.5. Flow Cytometry. BT- 474 and BT- $474_{\mathrm{EMT}}$ cells were analyzed for CD44 and CD24 expression using flow cytometry. Cells were washed once with phosphate-buffered saline (PBS) and then harvested with 0.05\% trypsin/0.025\% EDTA. Detached cells were washed with PBS that was supplemented with $0.2 \%(\mathrm{w} / \mathrm{v})$ bovine serum albumin (BSA) (wash buffer) and resuspended in the wash buffer $\left(10^{6}\right.$ cells $\left./ 100 \mu \mathrm{L}\right)$. Combinations of fluorochrome-conjugated monoclonal antibodies obtained from BioLegend (San Diego, CA) reactive against 
human and mouse CD44 (Alexa Fluor 647) and BD Pharmingen (San Jose, CA) CD24 (PE-Cy7) or their respective isotype controls were added to the cell suspension at concentrations recommended by the manufacturer and incubated at $4^{\circ} \mathrm{C}$ in the dark for 30 to $40 \mathrm{~min}$. The labeled cells were washed in the wash buffer and then analyzed on a MACSQuant Analyzer, MACS Miltenyi Biotec (Auburn, CA).

2.6. Cellular Uptake Studies. Fluorescently labeled $\mathrm{nCaP}^{\mathrm{CMHA}-\mathrm{AF} 488}$ was made via the method described in Section 2.2, with minor modifications. Briefly, Alexa Fluor 488 labeled CMHA was incorporated into the CMHA solution at $6 \%$ the total volume of CMHA used in the precipitation. All other reaction steps to create $\mathrm{nCaP}^{\mathrm{CMHA}}$ were performed the same way. BT- $474_{\mathrm{EMT}}$ cells were seeded at a density of $1 \times 10^{5}$ cells in an 8-well glass bottom plate and allowed to adhere for 24 hours after which $\mathrm{nCaP}{ }^{\mathrm{CMHA}-\mathrm{AF} 488}$ was added at the following concentrations: $200 \mu \mathrm{g} / \mathrm{mL}$, $1 \mathrm{mg} / \mathrm{mL}$, or $2 \mathrm{mg} / \mathrm{mL}$ in $500 \mu \mathrm{L}$ complete media. After 2 , 8 , and $18 \mathrm{~h}$ after incubation, the glass slide chambers were washed $2 \mathrm{x}$ with PBS to remove any loose nanoparticles, and the cells were fixed $4 \%$ paraformaldehyde in PBS for $15 \mathrm{~min}$. The fixed cells were washed with PBS $3 x$ to remove the excess paraformaldehyde and then dried for $3 \mathrm{~h}$. The fixed cells were stained and mounted with Prolong Gold antifade mounting media containing the nuclear stain 4',6-diamidino-2phenylindole (DAPI) (Thermo Fisher Scientific, Waltham, MA). Microscopic analysis was performed using a Nikon A1R Spectral Confocal Microscope. Conditions of the confocal microscopic analysis were a Z-stack thickness of $11 \mu \mathrm{m}$, individual stack thickness of $0.35 \mu \mathrm{m}$, and an oil immersed 40x objective.

2.7. Cytotoxicity. Cytotoxicity experiments were conducted using BT-474 (CD44 positive) and BT-474 ${ }_{\mathrm{EMT}}$ (CD44 negative) cells plated in 96-well plates at $6 \times 10^{4}$ and $2 \times 10^{5}$ cells/mL, respectively, with $50 \mu \mathrm{L}$ suspension per well. Two different seeding densities were used due to the very different growth rates of the cells during the cytotoxicity test. These cell types were selected to allow for the determination of cytotoxicity of $\mathrm{nCaP}^{\mathrm{CMHA}} \mathrm{CDDP}$ relative to $\mathrm{CD} 44$ expression and to elucidate if CMHA enhances cell uptake and consequently cytotoxicity. BT- 474 cells are CD44 negative and were thus used as a negative control. Cells were allowed to proliferate for 24 hours and then the test samples were added in an additional $50 \mu \mathrm{L}$ volume for a total of $100 \mu \mathrm{L}$ per well. The following groups were examined: CDDP, AqCDDP, and CMHA reacted with Aq CDDP (Aq CDDPCMHA), nCaP ${ }^{\mathrm{CMHA}} \mathrm{CDDP}, \mathrm{nCaP}^{\mathrm{CMHA}}$, and CMHA. Each group was serially diluted 1:3 across the plate using PBS. Cells were assayed $48 \mathrm{~h}$ after drug addition using in an MTS assay (CellTiter $96 \mathrm{AQ}_{\text {ueous }}$ One, G3580, Promega Corp., Madison, WI), where metabolic activity was determined using a Spectramax Plus ${ }^{384}$ Spectrophotometer (Molecular Biosciences, Sunnyvale, CA) at an absorbance of $490 \mathrm{~nm}$. To determine the IC50 (50\% inhibitory concentration) a nonlinear regression curve fit analysis was performed with at least four replicates per group per concentration. All experiments shown were repeated two to three times.

2.8. BT-474 ${ }_{E M T}$ Tumor Take Rate. To assess the growth parameters of BT- $474_{\mathrm{EMT}}$ tumors a tumor take rate study was performed in eight 6-8-week-old, immunocompromised athymic nude mice. Mice were given subcutaneous injections in the right rear flank via a 25-gauge needle of $5 \times 10^{5}$ cells in a $100 \mu \mathrm{L}$ volume of $\mathrm{BD}$ Matrigel and base media (ratio of 60:40) based on the cell number utilized for a comparable transformed breast cancer cell type [30]. Animals were monitored at least every other day for normal grooming and appearance. Tumors were measured beginning at day 7 following inoculation. At this time point the Matrigel carrier has degraded allowing for a true cell-based tumor volume measurement.

2.9. $n C a P{ }^{C M H A} C D D P$ In Vivo Maximum Tolerable Dose Determination. Two J:Nu immunocompromised mice with established BT-474 ${ }_{\mathrm{EMT}}$ tumors were injected once intratumorally with $10 \mathrm{mg} / \mathrm{kg} \mathrm{nCaP}{ }^{\mathrm{CMHA}} \mathrm{CDDP}(80-90 \mu \mathrm{L}$ per injection). A second study was conducted using athymic nude mice $(N=4)$, where a $7 \mathrm{mg} / \mathrm{kg}$ dose of $\mathrm{nCaP}{ }^{\mathrm{CMHA}} \mathrm{CDDP}$ $(60-70 \mu \mathrm{L})$ was administered once intratumorally. For both studies animals were monitored daily for weight loss and grooming and euthanized if weight loss met or exceeded $15 \%$.

2.10. $n C a P{ }^{C M H A} C D D P$ In Vivo Antitumor Efficacy and Toxicity Study. An efficacy and toxicity study was performed using BT-474 ${ }_{\mathrm{EMT}}$ cells in J:Nu mice. The study included 24 6-weekold mice inoculated with $5 \times 10^{5}$ BT- $474_{\mathrm{EMT}}$ cells in $100 \mu \mathrm{L}$ of a $60: 40$ ratio of BD Matrigel : cells in base media in the right rear flank via a 25 -gauge needle. Tumors were measured daily 7 days following inoculation using digital calipers to calculate the tumor volume assuming an ellipsoid shape: $V=(W)^{2} * L *$ 0.4. Tumors were treated once with $2.8 \mathrm{mg} / \mathrm{kg}(60 \mu \mathrm{L}) \mathrm{CDDP}$ $\mathrm{NT}$ ( 8 mice), $60 \mu \mathrm{L}$ of saline NT ( 4 mice), $60 \mu \mathrm{L}$ of $\mathrm{nCaP}^{\mathrm{CMHA}}$ $\mathrm{NT}$ ( 4 mice), or $7 \mathrm{mg} / \mathrm{kg} \mathrm{nCaP}{ }^{\mathrm{CMHA}} \mathrm{CDDP} \mathrm{NT}$ (8 mice), when tumor volume reached $100 \pm 10 \mathrm{~mm}^{3}$.

Systemic toxicity was evaluated by weight change and overall grooming/appearance. Tumor volume and mouse weight were monitored at least every other day. Mice were euthanized due to significant weight loss $(>15 \%)$, a tumor length measurement greater than $2 \mathrm{~cm}$, or completion of the study (day 30). At this time tumors were resected and weighed. All animal experimental procedures were approved by the Animal Care and Use Committee of the University of Connecticut Health Center (Farmington, CT).

2.11. Statistical Analysis. Statistical analysis was performed using an unpaired $t$-test (comparing two groups) or Tukey one-way ANOVA (comparing three or more test groups to a control group), as indicated in the methods. A $P$ value of less than 0.05 was considered statistically significant. Data is presented as a mean value with its standard deviation indicated (mean $\pm \mathrm{SD})$. 
TABLE 1: Average physical characteristics of $n \mathrm{CaP}^{\mathrm{CMHA}}$ CDDP. Ratio of components, precipitation volume, and stabilizer final concentration remained the same from batch to batch. Yield, CDDP concentration, drug loading, particle size, polydispersity, and zeta potential represent averages and standard deviations from a minimum of three batches.

\begin{tabular}{lc}
\hline Physical characteristic & $\mathrm{nCaP}{ }^{\mathrm{CMHA}} \mathrm{CDDP}$ \\
\hline Ca: P: Stabilizer $(\mathrm{v}: \mathrm{v}: \mathrm{v})$ & $2: 2: 1$ \\
Total precipitation volume $(\mathrm{mL})$ & 250 \\
Stabilizer final concentration $(\mathrm{mg} / \mathrm{mL})$ & 4 \\
Yield $(\mathrm{mg}$ nCaP/mL precipitation) & $2.3 \pm 0.4$ \\
CDDP concentration $(\mathrm{mg} / \mathrm{mL})$ & $4.1 \pm 1.4$ \\
Drug loading $(\mu \mathrm{g}$ CDDP/mg nCaP) & $140 \pm 12$ \\
Particle size $(\mathrm{nm})$ & $204 \pm 13 \mathrm{~nm}$ \\
Polydispersity & 0.116 \\
Zeta potential $(\mathrm{mV})$ & $-43 \pm 4$ \\
\hline
\end{tabular}

\section{Results and Discussion}

The physical characteristics of $\mathrm{nCaP}^{\mathrm{CMHA}} \mathrm{CDDP}$ are shown in Table 1. Precipitation of $\mathrm{nCaP}^{\mathrm{CMHA}}$ resulted in an efficient yield of $2.3 \pm 0.4 \mathrm{mg}$ per $\mathrm{mL}$ of precipitation solution. The CDDP concentration in the $\mathrm{nCaP}^{\mathrm{CMHA}} \mathrm{CDDP}$ suspension was $4.1 \pm 1.4 \mathrm{mg} / \mathrm{mL}$, with a drug loading of $140 \pm 12 \mu \mathrm{g}$ $\mathrm{CDDP} / \mathrm{mg} \mathrm{nCaP}{ }^{\mathrm{CMHA}}$. $\mathrm{nCaP}^{\mathrm{CMHA}} \mathrm{CDDP}$ were on average $204 \pm 13 \mathrm{~nm}$ in diameter as measured by dynamic light scattering with a polydispersity of 0.116 . The zeta potential of the particles was $-43 \pm 4 \mathrm{mV}$, which is greater than the colloidal stability threshold of $\pm 30 \mathrm{mV}$ thereby providing evidence of enhanced stability due to surface charge prevention of aggregation [31]. XRD data showed $\mathrm{nCaP}^{\mathrm{CMHA}}$ was poorly crystalline apatite based on the major peak occurring at $30^{\circ}$ which corresponds well with hydroxyapatite. MicroCaP made without the CMHA stabilizer was more crystalline in nature resembling brushite and poorly crystalline hydroxyapatite (Figure 2(a)) [32,33]. The introduction of CMHA clearly restricts the crystallization of $\mathrm{CaP}$, as can be seen by the broad peaks of $n \mathrm{CaP}^{\mathrm{CMHA}} \mathrm{XRD}$ spectra relative to the spectra of microCaP which exhibited a crystalline pattern with major peaks of hydroxyapatite as well as brushite (calcium hydrogen phosphate dehydrate, $\mathrm{CaHPO}_{4} \cdot 2 \mathrm{H}_{2} \mathrm{O}$ ). Transmission electron microscopy (TEM) (Figure 2(b)) revealed that $\mathrm{nCaP}{ }^{\mathrm{CMHA}} \mathrm{CDDP}$ in suspension forms small aggregates that correlate well with their measured particle size using DLS, $204 \pm 13 \mathrm{~nm}$. The addition of CMHA during precipitation of $\mathrm{CaP}$ resulted in successful stabilization of nCaP. TEM images revealed small $30-80 \mathrm{~nm}$ particles, agglomerated into larger particles, which likely accounts for the $200 \mathrm{~nm}$ size measured by DLS. These characteristics of the $\mathrm{nCaP}^{\mathrm{CMHA}} \mathrm{CDDP}$ resulted in a clog-free injectable nanoparticle suspension via a $25 \mathrm{G}$ needle.

To design an effective nanoparticle drug delivery system it is essential to optimize the physicochemical interactions of each component: the carrier, the drug, and any biological targeting moiety [34]. It was shown in previous work that sodium polyacrylate (Darvan $811, \mathrm{D}$ ) halts CaP crystal growth
[23]. This is due to the repeating carboxylate groups throughout the polymer. There is significant literature showing the carboxylate groups of sodium citrate (3 carboxylate groups per molecule) interact with the $\mathrm{Ca}$ ions during $\mathrm{CaP}$ precipitation acting as a surfactant to halt nucleation [22, 35-38]. Though these molecules effectively stabilize CaP, they have no biological targeting capacity. We therefore used a stabilizer that has biological targeting capability concurrent with $\mathrm{nCaP}$ stabilization. CMHA is a modified HA with additional carboxylate groups, thus allowing for more effective nCaP stabilization. CMHA at a degree of modification below 25\% binds to HA binding proteins with comparable affinity and avidity as native HA. Importantly, cross-linked hydrogels based on thiolated CMHA improve wound healing in cutaneous and ophthalmic injuries [39], allow delivery of small molecules as well as growth factors and other macromolecules [40], and are safe and effective vehicles for cell delivery and retention [40]. Clinical products based on CMHA are in development for cell therapy [41]. Thus, CMHA was selected to enhance uptake of $\mathrm{nCaP}^{\mathrm{CMHA}} \mathrm{CDDP}$ by cells expressing CD44. After confirming that a stable calcium phosphate nanoparticle was achieved, we tested whether these nanoparticles could bind, release, and maintain biological efficacy of CDDP. The in vitro release of the $\mathrm{nCaP}{ }^{\mathrm{CMHA}} \mathrm{CDDP}$ in $\mathrm{PBS}, \mathrm{pH} 7.4$, at $37^{\circ} \mathrm{C}$ over time can be seen in Figure 3. Under the rigorous, high speed and high volume release conditions $\mathrm{nCaP}{ }^{\mathrm{CMHA}} \mathrm{CDDP}$ exhibited a burst release of $73 \%$ of the CDDP bound in two days which plateaued and reached a total of $86 \%$ after seven days.

Surface plasmon resonance (SPR) was performed to assess the interaction and binding of CMHA, nCaP ${ }^{\mathrm{CMHA}} \mathrm{CDDP}$, and $\mathrm{HA}$ to $\mathrm{CD} 44$. Human $\mathrm{CD} 44$ chimera was immobilized on four channels of the sensor chip and two channels were amine coupled and blocked serving as a negative control for nonspecific binding. To correct for bulk shift due to the size of the nanoparticles, $\mathrm{nCaP}^{\mathrm{D}} \mathrm{CDDP}$ was examined as a control. As expected, HA most effectively bound to CD44 with CMHA approaching, but not equaling, the binding affinity of $\mathrm{HA}$ (Figure 4). $\mathrm{nCaP}^{\mathrm{CMHA}} \mathrm{CDDP}$ also binds CD44, but this binding is lower than free CMHA or HA. Importantly, this binding is specific as it overcomes any bulk interactions observed with $\mathrm{nCaP}^{\mathrm{D}} \mathrm{CDDP}$. SPR analysis of targeted nanoparticles is challenging. SPR systems utilize complex microfluidics that normally transport solutions containing ligands or proteins of interest, but generally not solid materials such as $\mathrm{nCaP}$. Of additional concern is the ability to correct for bulk shift due to the relatively large nanoparticles passing over the sensor. $\mathrm{nCaP}^{\mathrm{D}} \mathrm{CDDP}$ served as a comparably sized, nonspecific nanoparticle control. The density of the receptor (CD44) immobilized on the chip is inherently related to the response measured; therefore, we utilized a low density of CD44 on the chip surface [42]. The highest binding observed was for HA $(60 \mathrm{kDa})$, followed by CMHA $(34 \mathrm{kDa})$. The chemical modification of $\mathrm{HA}$ to create CMHA occurs at $15-20 \%$ of the repeating $6^{\prime}-\mathrm{OH}$ groups of the $\mathrm{N}$-acetylglucosamine residues. The interaction of CD44 and HA has low affinity but high avidity. A single HA disaccharide contains an N-acetyl-D-glucosamine and 


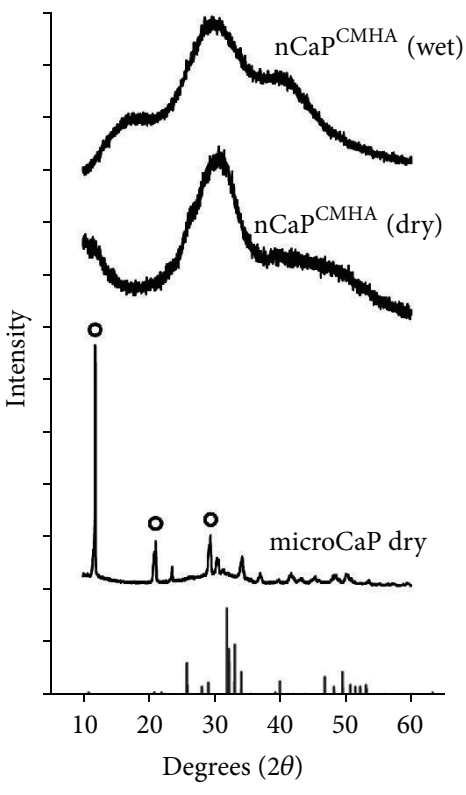

(a)

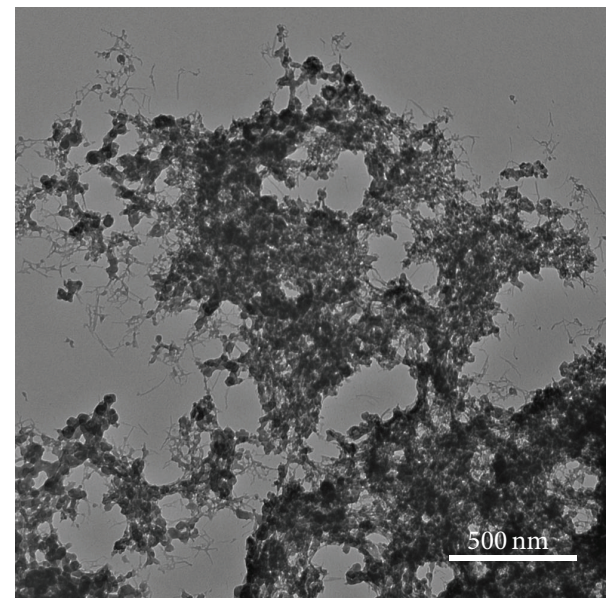

(b)

FIGURE 2: Physical characterization of $\mathrm{nCaP}^{\mathrm{CMHA}}$ using X-ray diffraction and transmission electron microscopy. (a) XRD spectra of nCaP $\mathrm{P}^{\mathrm{CMHA}}$ suspension ( $\mathrm{nCaP}^{\mathrm{CMHA}}$ wet), lyophilized $\mathrm{nCaP}^{\mathrm{CMHA}}$ ( $\mathrm{nCaP}^{\mathrm{CMHA}}$ dry), and lyophilized $\mathrm{CaP}$ without stabilizer added during precipitation (microCaP dry). Hydroxyapatite standard (JCPDS, \#09-0432, bars) is shown for comparison. nCaP ${ }^{\mathrm{CMHA}}$ both wet and dry has a major broad peak corresponding to the major peaks of hydroxyapatite. MicroCaP pattern has major peaks characteristic of brushite (peaks denoted by open circles). MicroCaP was precipitated without a stabilizer and has larger crystalline particles (narrow peaks). With the CMHA stabilizer present the crystallization is halted, depicted by broad peaks with little long range order. (b) TEM image of nCaP ${ }^{\mathrm{CMHA}} \mathrm{CDDP}$ showing particles $20-50 \mathrm{~nm}$ in diameter clustered into larger, $200 \mathrm{~nm}$, particles due to drying prior to imaging.

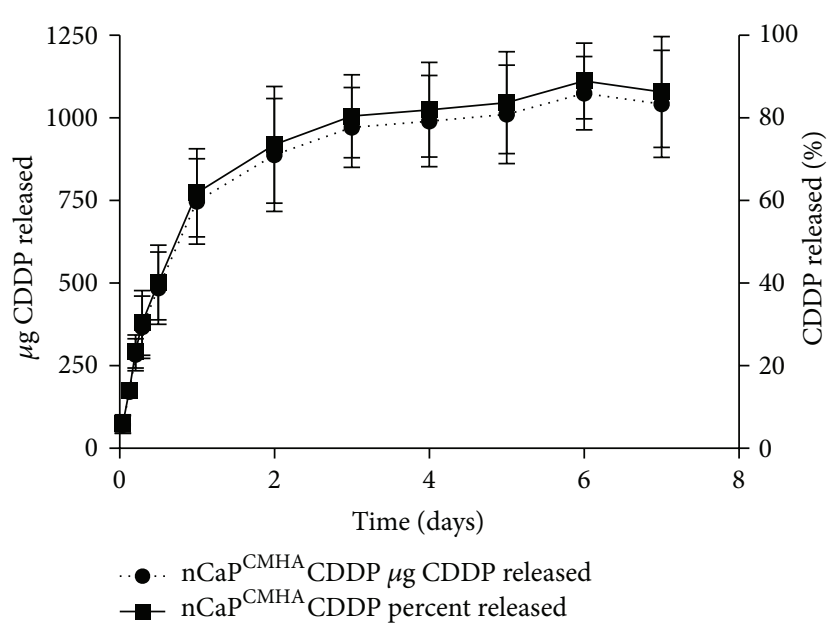

FIGURE 3: In vitro release testing of $\mathrm{nCaP}{ }^{\mathrm{CMHA}} \mathrm{CDDP}$ using a modified USP Apparatus 4. Release was conducted in $10 \mathrm{mM}$ PBS pH 7.4, 0.1\% sodium azide at $37^{\circ} \mathrm{C}$. The left axis is cumulative CDDP released with percent CDDP released on the right $y$-axis. The formulation provides sustained delivery of CDDP for 2 days under these infinite sink conditions. After 2 days nCaP ${ }^{\mathrm{CMHA}} \mathrm{CDDP}$ released $74 \%$ of the total CDDP bound. At day 7, $\mathrm{nCaP}^{\mathrm{CMHA}} \mathrm{CDDP}$ released an average of $86 \%$ of the total CDDP bound.

D-glucuronic acid, $\mathrm{HA}_{2}$. It has been shown that $\mathrm{HA}_{6}$ is necessary for binding $\mathrm{CD} 44$, but $\mathrm{HA}_{10}$ is preferred [43]. Additionally, divalent binding occurs with $\mathrm{HA}_{20}$ and larger oligomers. This likely explains the slight reduction in binding of CMHA to CD44, due to an interruption of sugar residues by the added carboxylate groups of CMHA compared to HA.
Flow cytometry analysis confirmed BT-474 are $1.71 \%$ positive for both CD44 and CD24 and the majority of cells stained positively for CD24 alone, 98.3\% (Figures 5(a)5(c)). These cells were thus a good negative control for CD44 targeting. BT-474 $4_{\mathrm{EMT}}$ cells stained $99.7 \%$ positive for CD44 and negative for CD24, which corresponds well to 

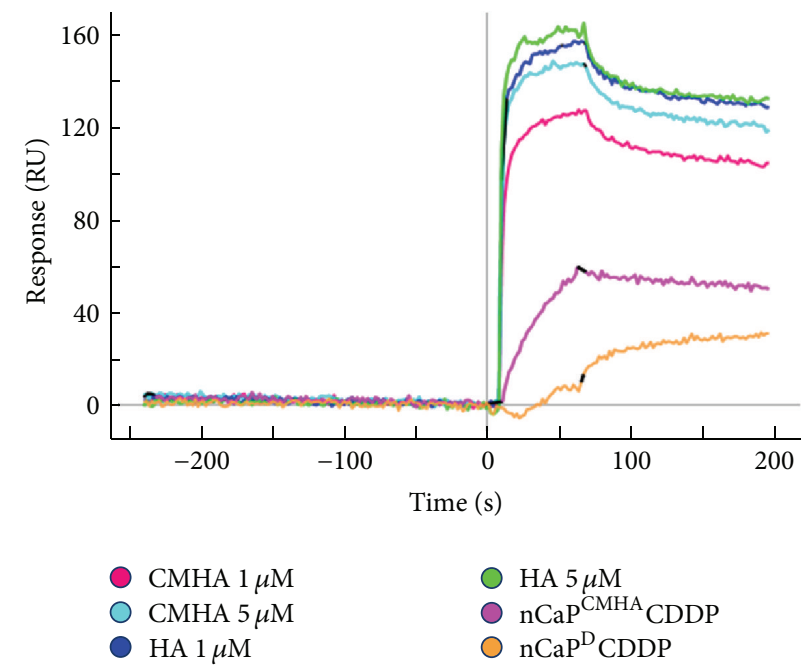

FIGURE 4: Surface plasmon resonance sensogram depicting binding of CMHA, HA, and nCaP ${ }^{\mathrm{CMHA}} \mathrm{CDDP}$ with immobilized CD44. All data shown has been corrected for nonspecific binding to blank channels of blocked NHS-EDC. $\mathrm{nCaP}^{\mathrm{D}} \mathrm{CDDP}$ was used as a comparable sized control, which does not have specific interactions with CD44. HA has the highest affinity for CD44, followed by CMHA then $\mathrm{nCaP}^{\mathrm{CMHA}} \mathrm{CDDP}$.

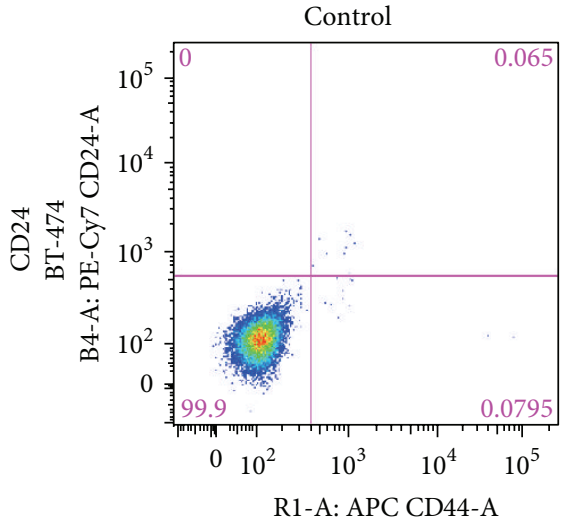

(a)

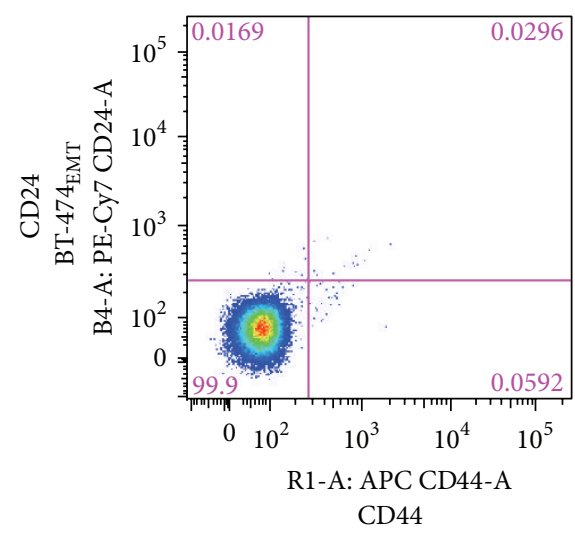

(d)

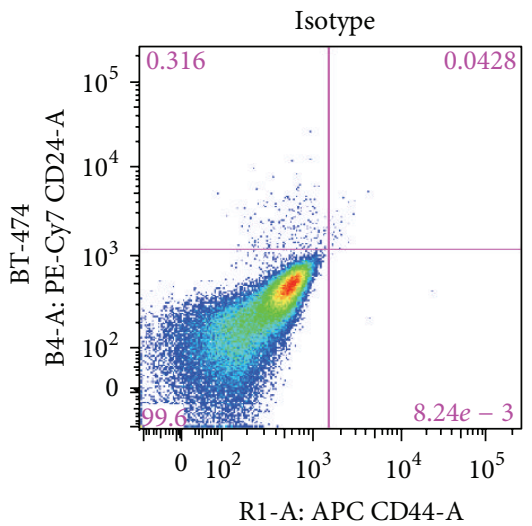

(b)

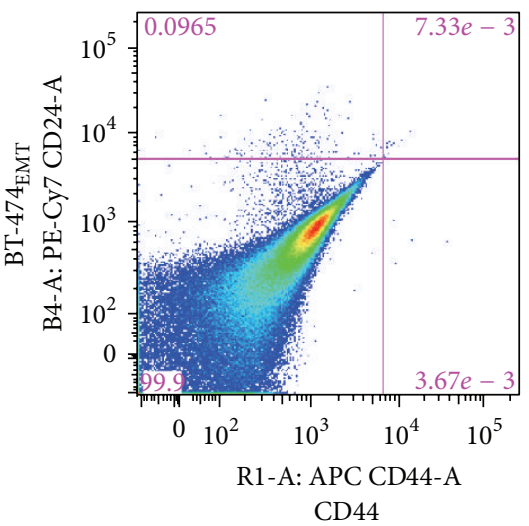

(e)

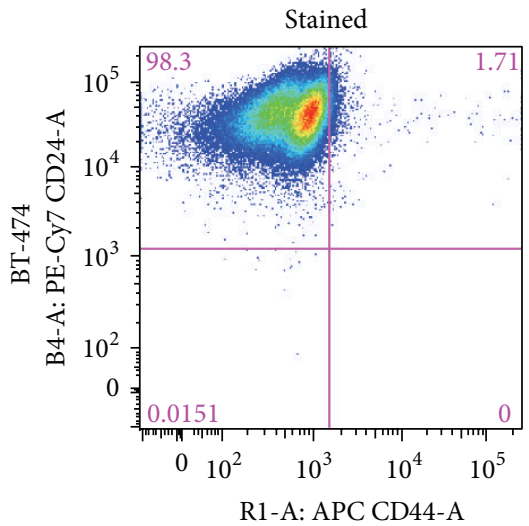

(c)

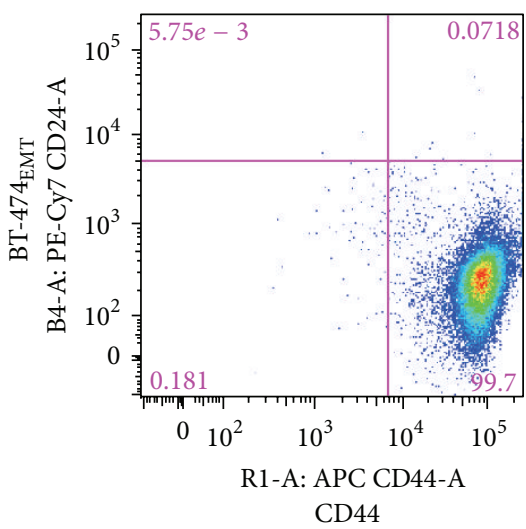

(f)

FIGURE 5: Flow cytometry data for the BT-474 and BT-474 $4_{\text {EMT }}$ cells demonstrates appropriate CD44 expression for the studies. The numbers in the corner of each quadrant are the percentage of positive cells within the quadrant. (a) BT-474 unstained control, (b) BT-474 isotype control, (c) BT-474 stained cells with CD44, Alexa Fluor 647, and CD24, PE-Cy7. BT- 474 cells are CD44 ${ }^{\text {low }} /$ CD2 $4^{\text {high }}$. These cells served as the negative control for CD44 targeting, because they lack CD44 expression. (d) BT-474 $4_{\mathrm{EMT}}$ unstained control, (e) BT-474 $4_{\mathrm{EMT}}$ isotype control, (f) BT- $474_{\mathrm{EMT}}$ stained cells with CD44, Alexa Fluor 647, and CD24, PE-Cy7. BT- $474_{\mathrm{EMT}}$ cells are CD $44^{+} / \mathrm{CD} 24^{\text {low }}$. These cells were tested to investigate CD44 targeting, as they have high CD44 expression. 


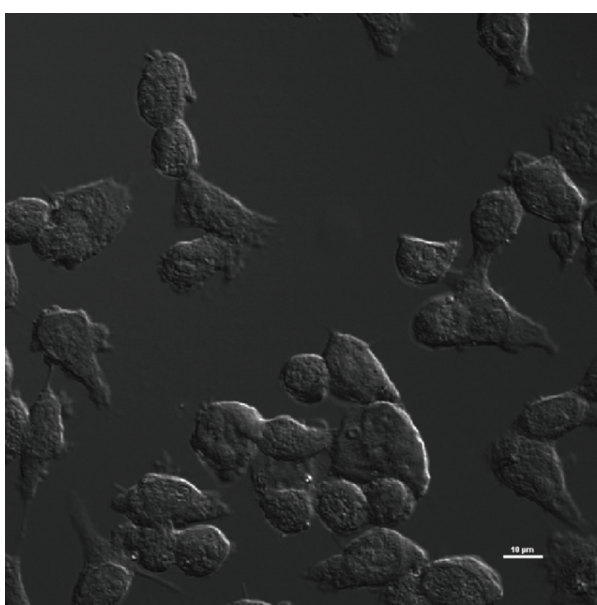

(a)

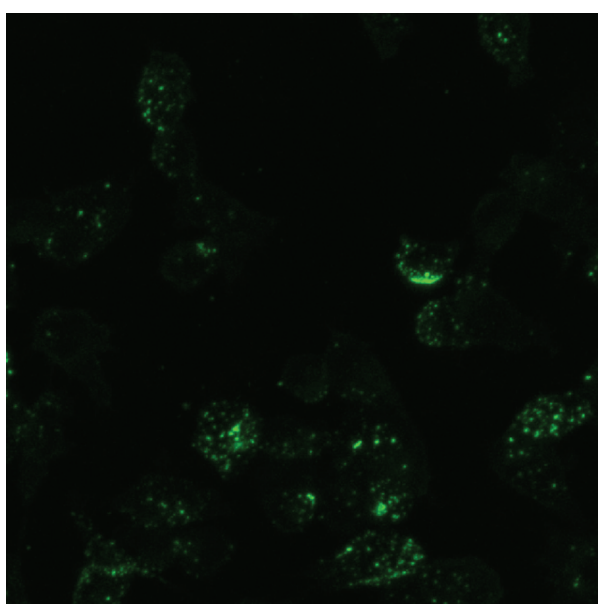

(c)

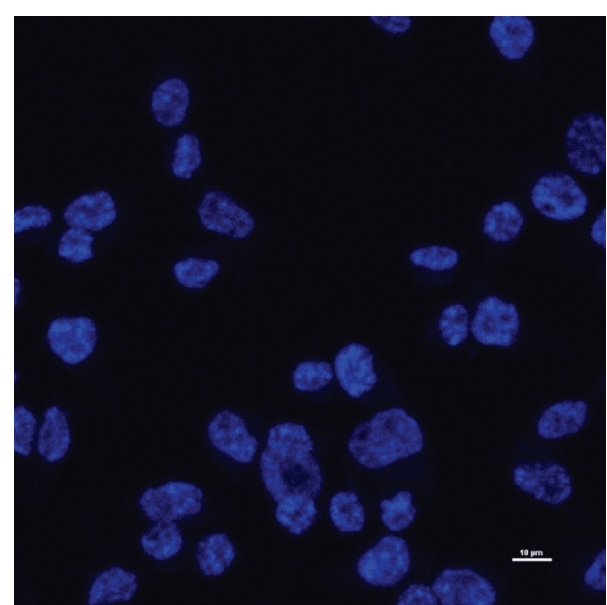

(b)

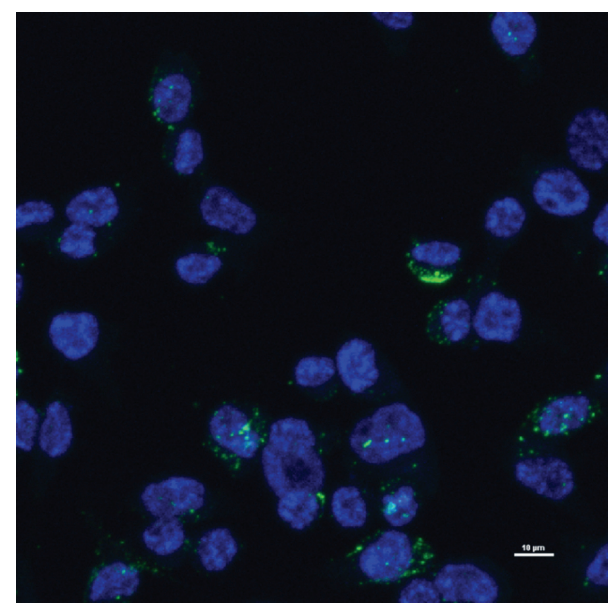

(d)

FIgure 6: Cellular uptake study using BT-474 ${ }_{\mathrm{EMT}}$ cells. Cells were plated and allowed to adhere for 24 hours, after which nCaP ${ }^{\mathrm{CMHA}-\mathrm{AF} 488}$ was added at a concentration of $2 \mathrm{mg} / \mathrm{mL}$. After 18 hours, $\mathrm{nCaP}^{\mathrm{CMHA}-\mathrm{AF} 488}$ can clearly be seen within cells as confirmed by Z-stack confocal images. (a) Differential interference contrast (DIC) image, (b) cells stained with DAPI, (c) cells imaged containing nCaPCMHA-AF488, and (d) overlay of DAPI and AF488 images, showing $\mathrm{nCaP}^{\mathrm{CMHA}-\mathrm{AF} 488}$ uptake.

the phenotype of therapy resistant breast cancer cells in the literature, $\mathrm{CD} 44^{+} / \mathrm{CD} 24^{-/ \text {low }}$ (Figures 5(d)-5(f)) [11, 44]. BT$474_{\mathrm{EMT}}$ cells were therefore used as the $\mathrm{CD} 44^{+}$test groups of cells to examine CD44 specificity with cellular uptake and cytotoxicity of $\mathrm{nCaP}^{\mathrm{CMHA}-\mathrm{AF} 488}$. In the cell uptake studies no significant uptake was determined for the $200 \mu \mathrm{g} / \mathrm{mL}$ or $1 \mathrm{mg} / \mathrm{mL}$ concentrations at any time tested (images not shown). At the $2 \mathrm{mg} / \mathrm{mL}$ dose, significant cellular uptake was determined at 18 hours posttreatment (Figures 6(a)-6(d)). Zstack images were obtained, confirming the $\mathrm{nCaP}^{\mathrm{CMHA}-\mathrm{AF} 488}$ was within the cell with nuclei counterstained with DAPI. This was a preliminary test of cellular uptake. These were insufficient to prove that $\mathrm{nCaP}^{\mathrm{CMHA}-\mathrm{AF} 488}$ cellular uptake was mediated by CD44. To do so, at least two controls are necessary, a CD $44^{-}$cell type and a $\mathrm{CD} 44^{+}$cell type pretreated with HA to saturate the CD44 receptors [45] and should be included in future studies. SPR showed $\mathrm{nCaP}^{\mathrm{CMHA}} \mathrm{CDDP}$ had lower binding than CMHA, which is likely due to two factors. Only $30 \%$ of the $4 \mathrm{mg} / \mathrm{mL}$ CMHA in the precipitation is incorporated into $\mathrm{nCaP}^{\mathrm{CMHA}}$. Additionally, $\mathrm{nCaP}{ }^{\mathrm{CMHA}} \mathrm{CDDP}$ is stored as a suspension which allows the $\mathrm{CaP}$ to undergo Ostwald ripening incorporating much of the CMHA within the $\mathrm{nCaP}$ core $[46,47]$. The exposure time required for cellular uptake of nCaP ${ }^{\mathrm{CMHA}-\mathrm{AF} 488}$ was more than four times that of mesoporous silica nanoparticles targeted to CD44 via HA, where a $200 \mathrm{kDa} H A$ was used [15].

The cytotoxicity of CMHA, $\mathrm{nCaP}^{\mathrm{CMHA}}, \mathrm{CDDP}, \mathrm{Aq} \mathrm{CDDP}$, Aq CDDP-CMHA, and $\mathrm{nCaP}^{\mathrm{CMHA}} \mathrm{CDDP}$ was examined against BT-474 (CD44 negative) and BT-474 $4_{\mathrm{EMT}}$ (CD44 positive) cells. These studies confirmed that CMHA did not have any inherent toxicity to either cell type (Figure 7(a)). The CMHA stabilized $\mathrm{nCaP}{ }^{\mathrm{CMHA}}$ also had no cytotoxicity when tested at the concentrations which matched the amount of $\mathrm{nCaP}$ in the $\mathrm{nCaP}^{\mathrm{CMHA}} \mathrm{CDDP}$ test groups (Figure $7(\mathrm{~b})$ ). The IC50 curves of CDDP, Aq CDDP, and Aq CDDP reacted with CMHA (Aq CDDP-CMHA), and $\mathrm{nCaP}^{\mathrm{CMHA}} \mathrm{CDDP}$ against 


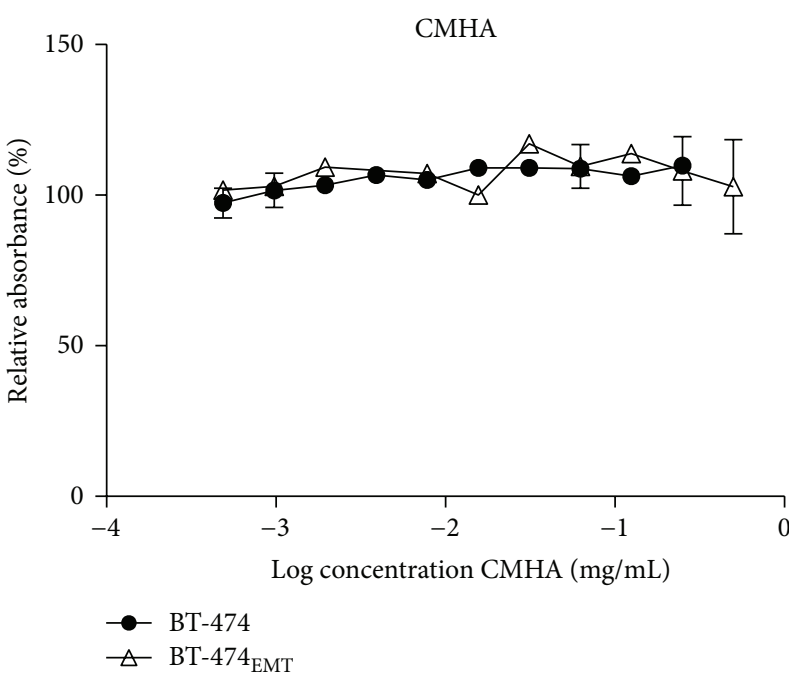

(a)

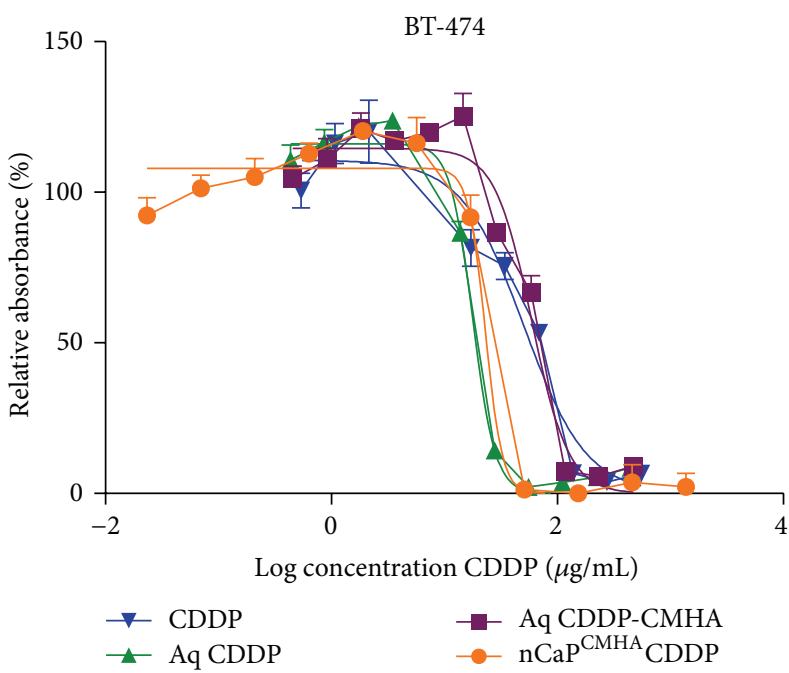

(c)

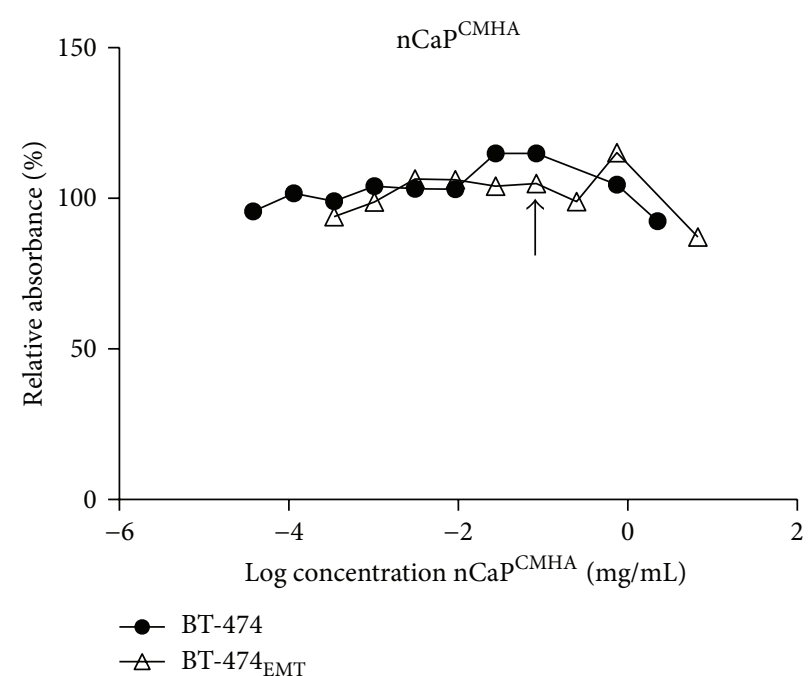

(b)

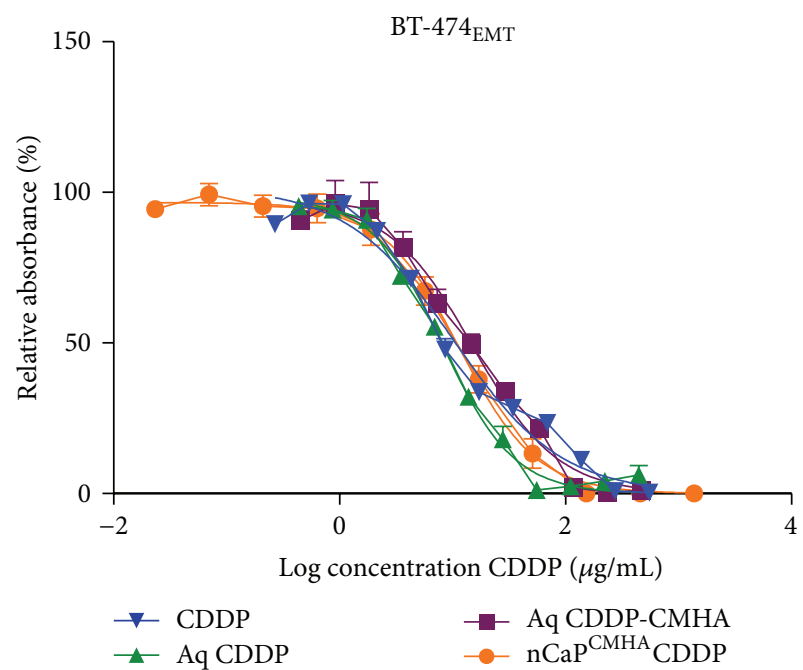

(d)

Figure 7: Cytotoxicity examination of CMHA, nCaP ${ }^{\mathrm{CMHA}}$, CDDP, Aq CDDP, Aq CDDP-CMHA and nCaP ${ }^{\mathrm{CMHA}}$ CDDP evaluated against BT474 and BT-474 EMT cells using an MTS assay. (a) Evaluation of CMHA alone against BT-474 and BT-474 $4_{\text {EMT }}$ cells, showing no cytotoxicity. (b) Evaluation of $\mathrm{nCaP}{ }^{\mathrm{CMHA}}$ alone against BT-474 and BT-474 ${ }_{\mathrm{EMT}}$ cells, showing no cytotoxicity. (c) Cytotoxicity evaluation using BT-474 $\left(\mathrm{CD} 44^{-}\right)$cells. CDDP, Aq CDDP, and Aq CDDP reacted with CMHA (Aq CDDP-CMHA), and nCaP ${ }^{\mathrm{CMHA}} \mathrm{CDDP}$ curves are plotted. (d) Cytotoxicity evaluation using BT-474 ${ }_{\mathrm{EMT}}\left(\mathrm{CD} 44^{+}\right)$cells. CDDP, Aq CDDP, and Aq CDDP reacted with CMHA (Aq CDDP-CMHA), and $\mathrm{nCaP}{ }^{\mathrm{CMHA}} \mathrm{CDDP}$ curves are plotted.

BT-474 cells are shown in Figure 7(c). The IC50 curves of CDDP, Aq CDDP, and Aq CDDP reacted with CMHA (Aq CDDP-CMHA), and $\mathrm{nCaP}{ }^{\mathrm{CMHA}} \mathrm{CDDP}$ against $\mathrm{BT}-474_{\mathrm{EMT}}$ cells are shown in Figure 7(d). The IC50 values calculated from these curve fits are shown in Table 2. $\mathrm{nCaP}^{\mathrm{CMHA}} \mathrm{CDDP}$ and Aq CDDP were significantly more cytotoxic than CDDP alone against BT-474 cells and Aq CDDP-CMHA was significantly less cytotoxic $(P \leq 0.001)$. $\mathrm{nCaP}^{\mathrm{CMHA}} \mathrm{CDDP}$ had comparable cytotoxicity to CDDP against BT-474 $\mathrm{EMT}_{\mathrm{T}}$ cells. Aq CDDP-CMHA was significantly less cytotoxic than CDDP $(P \leq 0.001)$ and Aq CDDP was significantly more cytotoxic $(P \leq 0.05)$ for BT-474 $4_{\mathrm{EMT}}$ cells.
Interestingly, $\mathrm{nCaP}{ }^{\mathrm{CMHA}} \mathrm{CDDP}$ did not show preferential cytotoxicity to cells with high CD44 expression (BT$474_{\mathrm{EMT}}$ ) compared to those with negative CD44 expression (BT-474), or compared to CDDP alone. It was hypothesized $\mathrm{nCaP}{ }^{\mathrm{CMHA}} \mathrm{CDDP}$ would target cells with high $\mathrm{CD} 44$ expression causing increased cytotoxicity. In related studies, mesoporous silica nanoparticles targeted with HA and carrying doxorubicin were significantly more cytotoxic than doxorubicin alone against CD44 expressing cells but were significantly less cytotoxic to CD44 negative cells [16]. Similarly, an HA Taxol prodrug was more cytotoxic than free Taxol against cells expressing CD44 and had limited to no 


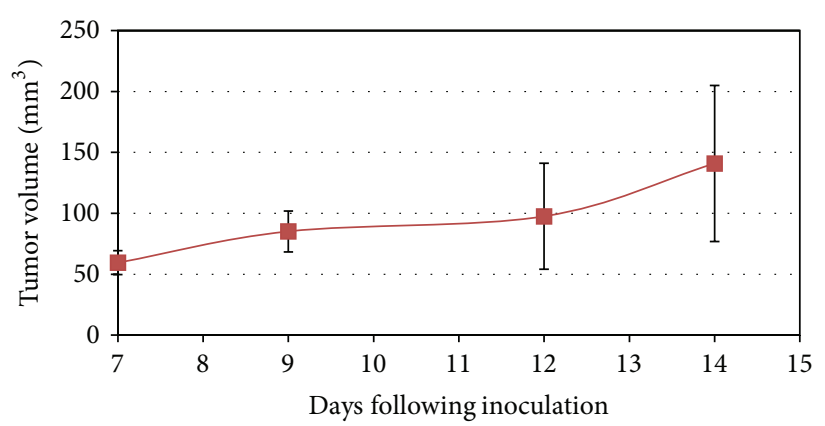

(a)

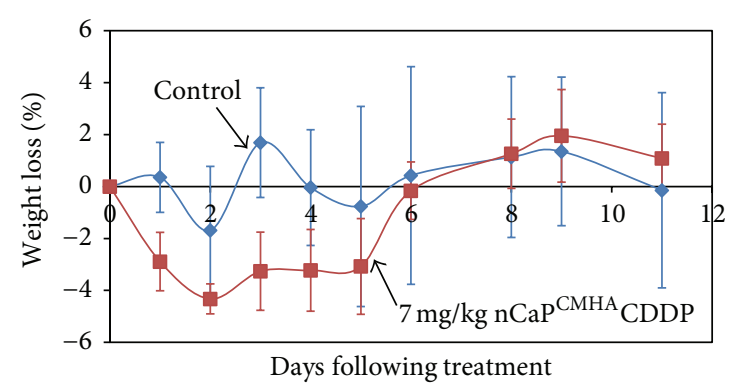

(b)

FIGURE 8: In vivo tumor take rate and maximum tolerable dose studies. (a) Tumor take rate study performed in athymic nude mice with 5 $\times 10^{5}$ BT- $474_{\text {EMT }}$ cells injected subcutaneously in right rear flank of animals. Data represents average tumor volume versus days following inoculation with standard deviations. (b) Maximum tolerable dose study conducted with athymic nude mice (6-8 weeks old) carrying BT$474_{\mathrm{EMT}}$ tumors. An intratumoral $7 \mathrm{mg} / \mathrm{kg}$ dose of $\mathrm{nCaP}{ }^{\mathrm{CMHA}} \mathrm{CDDP}$ (4 mice/group) was compared to an untreated control (4 mice/group). $\mathrm{nCaP}{ }^{\mathrm{CMHA}} \mathrm{CDDP}$ caused minimal weight loss at $7 \mathrm{mg} / \mathrm{kg}$ and all animals recovered.

TABLE 2: Tabulated IC50 values of CDDP, Aq CDDP, Aq CDDP-CMHA, and nCaP ${ }^{\mathrm{CMHA}}$ CDDP examined with BT-474 and BT-474 ${ }_{\mathrm{EMT}}$ cells, from curves shown in Figures $7(\mathrm{a})$ and $7(\mathrm{~b})$, respectively. For BT-474 cells Aq CDDP and nCaP ${ }^{\mathrm{CMHA}} \mathrm{CDDP}$ were both significantly more effective than CDDP alone and Aq CDDP-CMHA was significantly less effective than CDDP. For BT-474 $\mathrm{EMT}_{\mathrm{C}} \mathrm{cells} \mathrm{nCaP}^{\mathrm{CMHA}} \mathrm{CDDP}$ was as cytotoxic as CDDP alone and Aq CDDP was significantly more effective while Aq CDDP-CMHA was significantly less effective.

\begin{tabular}{lcccc}
\hline Cell type & CDDP & Aq CDDP & $\begin{array}{r}\text { IC50 }(\mu \mathrm{g} / \mathrm{mL}) \\
\text { Aq CDDP-CMHA }\end{array}$ & nCaP ${ }^{\mathrm{CMHA}}$ CDDP \\
\hline BT-474 & $50.6 \pm 3.3$ & $17.1 \pm 0.9^{\mathrm{c}}$ & $59.0 \pm 2.7^{\mathrm{c}}$ & $23.1 \pm 3.9^{\mathrm{c}}$ \\
\hline BT-474 EMT & $10.5 \pm 1.1$ & $8.78 \pm 0.6^{\mathrm{a}}$ & $16.24 \pm 1.5^{\mathrm{c}}$ & $12.1 \pm 1.4$ \\
\hline
\end{tabular}

${ }^{\mathrm{a}} P \leq 0.05$.

${ }^{\mathrm{c}} P \leq 0.001$.

cytotoxicity against cells that did not express CD44 [13, 14]. These studies demonstrate a specific CD44 mediated uptake in the HA containing particles that allowed the drug to release intracellularly, where cells lacking CD44 did not take up the prodrug. Possible reasons for the opposite findings in our studies are as follows. While $\mathrm{nCaP}^{\mathrm{CMHA}}$ was taken up by BT$474_{\mathrm{EMT}}$ cells, the uptake was relatively slow compared to other HA nanoparticle formulations which were taken up after 4 hours of exposure $[15,16]$. The SPR data implies that the HA presentation after adsorption to the $\mathrm{CaP}$ was not optimal. The future use of CMHA with greater spacing between the carboxylate groups may overcome this. Additionally it was expected that the BT-474 $4_{\mathrm{EMT}}$ cells would be chemotherapy resistant and would require a carrier to enhance effectiveness of CDDP, since comparable mesenchymal-derived MCF-7 cells were resistant to other chemotherapies (docetaxel and tamoxifen) [11, 30]. However, the cytotoxicity data shows that BT-474 $4_{\mathrm{EMT}}$ cells are sensitive to CDDP as compared to BT-474 cells without CD44. The major adducts caused by CDDP are 1,2-intrastrand cross-links that interfere with DNA replication and transcription resulting in cell death during G2 phase prior to mitosis [48]. Unexpectedly the $\mathrm{nCaP}^{\mathrm{CMHA}} \mathrm{CDDP}$ was more cytotoxic than CDDP alone against the BT-474 cells without CD44. The controlled release of $\mathrm{CDDP}$ from $\mathrm{nCaP}{ }^{\mathrm{CMHA}} \mathrm{CDDP}$ allowed for prolonged delivery of drug to the slower replicating BT-474 cells, which could explain the enhanced cytotoxicity of $\mathrm{nCaP}^{\mathrm{CMHA}} \mathrm{CDDP}$ over CDDP alone.

Importantly, the $\mathrm{nCaP}^{\mathrm{CMHA}} \mathrm{CDDP}$ had equivalent cytotoxicity to CDDP in vitro which means $\mathrm{nCaP} \mathrm{PMHA}^{\mathrm{CM}}$ had no negative impact on the biological activity of CDDP and thus these particles were suitable candidates for evaluation in an in vivo tumor model. The in vivo tumor forming capability of BT-474 $4_{\text {EMT }}$ cells had not been previously studied; therefore, their ability to form tumors was first examined in a tumor take rate study. BT- $474_{\mathrm{EMT}}$ tumors formed after cell injections were $50 \mathrm{~mm}^{3}$ on average after 7 days. After approximately 12 days tumors were $100 \mathrm{~mm}^{3}$ (Figure 8(a)). Animals were monitored for 25 days following inoculation where tumors continued to grow steadily up to $500 \mathrm{~mm}^{3}$ without necrosis. The comparable mesenchymal-derived human MCF-7 human BC cells were also tested under the same conditions in an in vivo tumor model and were found to have similar growth rates as the $\mathrm{BT}-474_{\mathrm{EMT}}$ with volumes reaching $500 \pm$ $100 \mathrm{~mm}^{3}$ at 20 days following inoculation [30]. These studies confirmed that this new human breast cancer tumor model BT-474 EMT was not too fast growing and did not develop necrotic tumors.

A maximum tolerable dose (MTD) study was conducted in mice bearing BT-474 $4_{\mathrm{EMT}}$ tumors. Based on a small pilot 


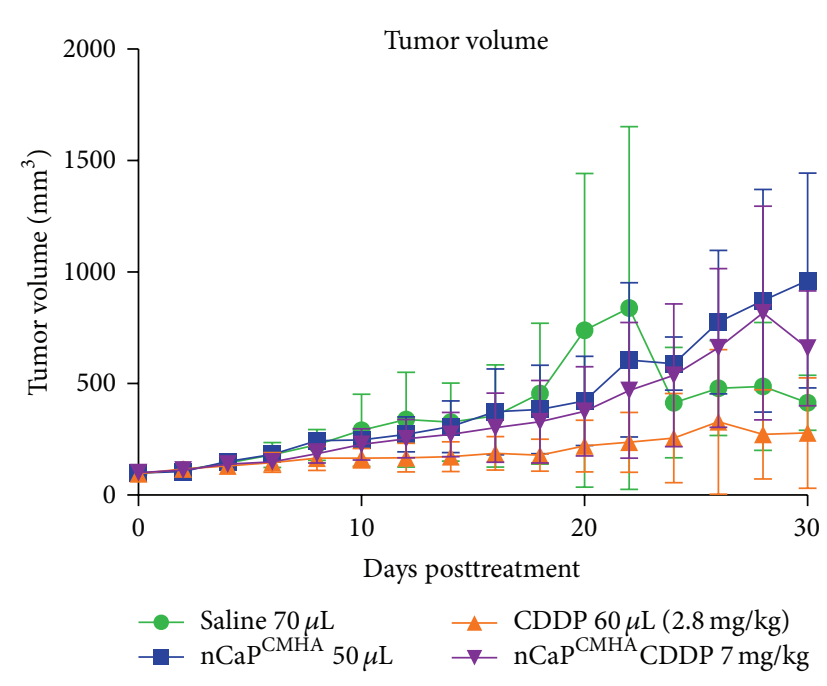

(a)

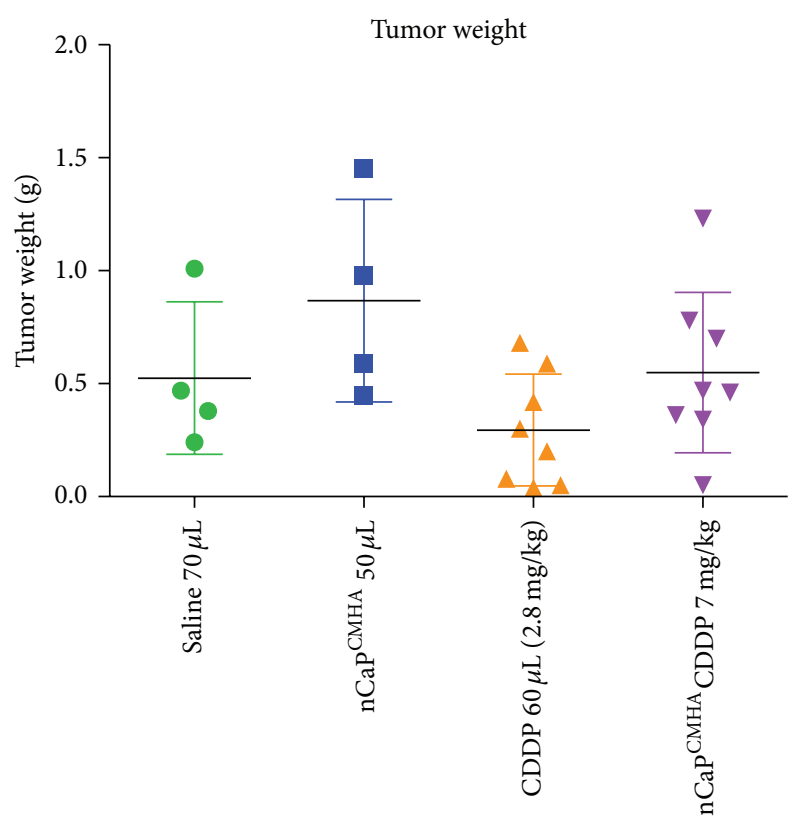

(b)

FIGURE 9: Efficacy study of $\mathrm{nCaP}^{\mathrm{CMHA}} \mathrm{CDDP}$ conducted on J:Nu mice bearing BT-474 $\mathrm{EMT}$ tumors. Animals were treated once when their tumor volume reached $100 \pm 10 \mathrm{~mm}^{3}$ and were compared to $2.8 \mathrm{mg} / \mathrm{kg} \mathrm{CDDP}$ administered near the tumor. Tumor volume, grooming, and weight loss were monitored every other day following treatment. (a) The graph depicts average tumor volume $\left(\mathrm{mm}^{3}\right)$ per group versus days posttreatment. The negative control saline IT $(70 \mu \mathrm{L})$ had no effect on tumor growth. nCaP ${ }^{\mathrm{CMHA}}(60 \mu \mathrm{L})$ had no effect on tumor growth. $\mathrm{CDDP}$ at $2.8 \mathrm{mg} / \mathrm{kg}$ administered near the tumor delayed tumor growth. (b) Tumor weight at the end of the study or at time of euthanasia for the efficacy study shown in (a). Tumors were resected and weighed. Animals were euthanized if tumor diameter was measured $>2 \mathrm{~cm}$ or at the completion of the study (day 30 ). No significant differences were found between groups.

study showing excessive weight loss in at least one mouse mice treated with $10 \mathrm{mg} / \mathrm{kg} \mathrm{nCaP}^{\mathrm{CMHA}} \mathrm{CDDP}$, mice were given $7 \mathrm{mg} / \mathrm{kg} \mathrm{nCaP}{ }^{\mathrm{CMHA}} \mathrm{CDDP}(60-70 \mu \mathrm{L})$ intratumorally into tumors with an average tumor volume of $170 \mathrm{~mm}^{3}$, 14 days following cell inoculation. The results are shown in Figure 8(b), where the maximum weight loss was 5\% occurring at two to five days following treatment. This is an acceptable weight loss during treatment with chemotherapeutics; therefore, this dose was deemed tolerable and used for the antitumor studies.

To assess the antitumor efficacy of the $\mathrm{nCaP}^{\mathrm{CMHA}} \mathrm{CDDP}$, tumors were treated once by direct injection near the tumor with one of the following treatments: $2.8 \mathrm{mg} / \mathrm{kg}(60 \mu \mathrm{L})$ $\mathrm{CDDP}$ (8 mice), $60 \mu \mathrm{L}$ of saline ( 4 mice), $60 \mu \mathrm{L}$ of nCaP ${ }^{\mathrm{CMHA}}$ (4 mice), or $7 \mathrm{mg} / \mathrm{kg} \mathrm{nCaP}{ }^{\mathrm{CMHA}} \mathrm{CDDP}$ (8 mice), when tumor volume reached $100 \pm 10 \mathrm{~mm}^{3}$. No significant differences in tumor volume or weights were found among groups (Figure 9(a)), even the positive control (CDDP only). No animal experienced weight loss greater than $2 \%$ at these doses (data not shown). At the time of euthanasia, tumors were resected and weighed to compare to volumetric measurements. The resulting tumor weights were plotted relative to treatment (Figure 9(b)). No significant differences were found between groups when analyzed according to tumor weight. No treatment caused toxicity to the animals as measured by weight loss and overall grooming/appearance.
Survival over time posttreatment was evaluated for each group (Figure 10). Mice were not actually allowed to die due to the treatments or tumor growth; instead they were euthanized if the tumors reached a tumor length measurement greater than $20 \mathrm{~mm}$. In this slow growing model half of the untreated animals still had small tumors at the end point of the study making it difficult to observe large changes in tumor size due to treatment. Large standard deviations of tumor volume in the untreated group (as well as treatment group) were another problem obscuring differences between groups. In our studies with the $\mathrm{FaDu}$ (human head and neck squamous cell carcinoma) tumor model, it was necessary to use a larger number of cells $\left(2 \times 10^{6}\right.$ cells $)$ to achieve reproducible growth rather than $5 \times 10^{5}$ cells (which was used in these studies with the BT- $474_{\mathrm{EMT}}$ ). If a higher number of BT-474 $4_{\mathrm{EMT}}$ cells were injected, limited variability in tumor volume might have occurred enabling a more discriminating evaluation of the test groups.

At the time of resection, depots of $\mathrm{nCaP}{ }^{\mathrm{CMHA}} \mathrm{CDDP}$ of a similar size to that injected were observed adjacent to the tumor on one or both sides indicating the $\mathrm{nCaP}$ was not resorbed or degraded over one month of implantation. Visual observations of the placement of the material allowed us to make a correlation between treatment placement and efficacy. The $\mathrm{nCaP}{ }^{\mathrm{CMHA}} \mathrm{CDDP}$ had the greatest antitumor effect when it was evenly distributed around the tumor. The lack of an 


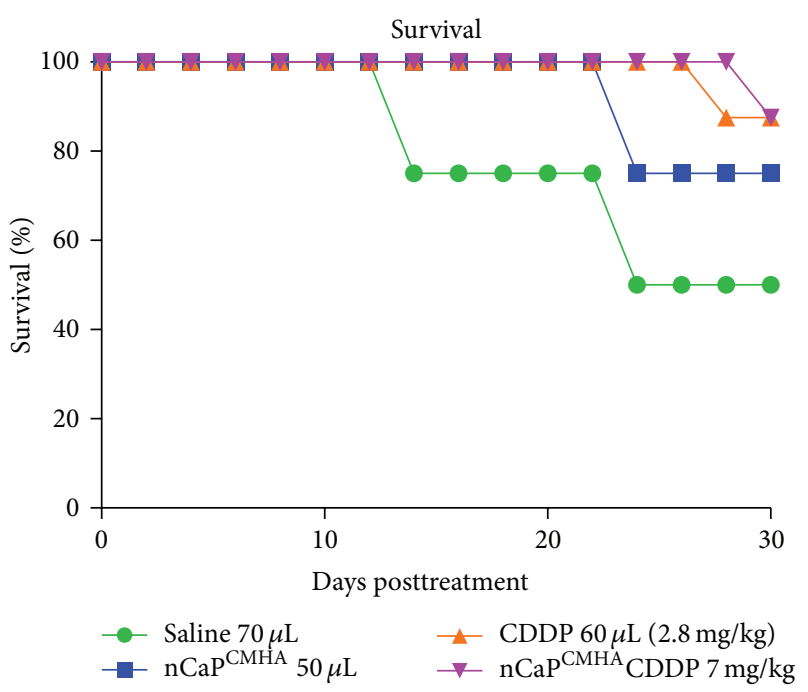

FIgURE 10: Survival was plotted for the efficacy study shown in Figure 9. The study was conducted on J:Nu mice bearing BT$474_{\mathrm{EMT}}$ tumors. Animals were treated once when their tumor volume reached $100 \pm 10 \mathrm{~mm}^{3}$ and compared to $2.8 \mathrm{mg} / \mathrm{kg}$ CDDP administered near tumor (NT). Tumor volume, grooming, and weight loss were monitored every other day following treatment. Survival was defined as a tumor diameter $>2 \mathrm{~cm}$ or inability to groom. A treatment of $7 \mathrm{mg} / \mathrm{kg} \mathrm{nCaP}{ }^{\mathrm{CMHA}} \mathrm{CDDP}$ and $2.8 \mathrm{mg} / \mathrm{kg}$ CDDP (NT) was most effective at prolonging survival compared to control treatments of saline or $\mathrm{nCaP}^{\mathrm{CMHA}}(\mathrm{NT})$.

even distribution $\mathrm{nCaP}{ }^{\mathrm{CMHA}} \mathrm{CDDP}$ may have contributed to the lack of antitumor efficacy observed in these animals. $\mathrm{nCaP}{ }^{\mathrm{CMHA}} \mathrm{CDDP}$ did not freely diffuse throughout the tumor due to the density of the tumor, and therefore only the areas of the tumor proximal to the $\mathrm{nCaP}^{\mathrm{CMHA}} \mathrm{CDDP}$ depot were exposed to the CDDP. It is likely that the ability of free CDDP to diffuse throughout the tumor caused the more reproducible tumor growth inhibition observed in the CDDP alone group. Intravenous administration of the nanoparticles may allow for greater penetration of the treatment into the tumor interior with an associated increased antitumor effect. A recently published clinical trial shows that neoadjuvant CDDP intravenous treatment was effective for patients with TNBC, though this treatment has not yet been adopted clinically [49]. Therefore, continued investigations on CDDP delivery systems are warranted for TNBC.

\section{Conclusions}

CMHA is a novel and effective stabilizer for $\mathrm{nCaP}$ that can bind to CD44 receptors for potential targeting applications. Importantly, it was determined that CMHA has no negative impact on the biological activity of CDDP in vitro, against human breast cancer cells. $\mathrm{nCaP}{ }^{\mathrm{CMHA}} \mathrm{CDDP}$ allowed for efficient release of CDDP. $\mathrm{nCaP}^{\mathrm{CMHA}} \mathrm{CDDP}$ had equivalent cytotoxicity to CDDP alone against $\mathrm{CD} 44^{+}$cells and was more cytotoxic for $\mathrm{CD} 44^{-}$cells. Tumors are very heterogeneous in cell surface expression and therefore cytotoxicity to both $\mathrm{CD} 44^{+}$and $\mathrm{CD} 44^{-}$cells is important in vivo. In future studies, an intravenous dose of $\mathrm{nCaP}^{\mathrm{CMHA}} \mathrm{CDDP}$ at the maximum tolerable dose with optimized cell uptake and tumor infiltration should be examined in vivo to evaluate the targeting of therapy resistant $\mathrm{CD} 44^{+}$cells by chemically modified HA.

\section{Conflict of Interests}

The authors declare that there is no conflict of interests regarding the publication of this paper.

\section{Acknowledgments}

The authors would like to acknowledge financial support from the University of Connecticut's 2012 UCHC/Storrs and Regional Campus Incentive Grant (UCIG) to Drs. Diane J. Burgess and Liisa T. Kuhn.

\section{References}

[1] American Cancer Society, Cancer Facts \& Figures, American Cancer Society, Atlanta, Ga, USA, 2013.

[2] A. M. Brewster, G. N. Hortobagyi, K. R. Broglio et al., "Residual risk of breast cancer recurrence 5 years after adjuvant therapy," Journal of the National Cancer Institute, vol.100, no. 16, pp. 11791183, 2008.

[3] M. D. Curley, L. A. Garrett, J. O. Schorge, R. Foster, and B. R. Rueda, "Evidence for cancer stem cells contributing to the pathogenesis of ovarian cancer," Frontiers in Bioscience, vol. 16, no. 1, pp. 368-392, 2011.

[4] K. D. Steffensen, A. B. Alvero, Y. Yang et al., "Prevalence of epithelial ovarian cancer stem cells correlates with recurrence in early-stage ovarian cancer," Journal of Oncology, vol. 2011, Article ID 620523, 12 pages, 2011.

[5] H. E. Lee, J. H. Kim, Y. J. Kim et al., "An increase in cancer stem cell population after primary systemic therapy is a poor prognostic factor in breast cancer," British Journal of Cancer, vol. 104, no. 11, pp. 1730-1738, 2011.

[6] A. B. Alvero, R. Chen, H.-H. Fu et al., "Molecular phenotyping of human ovarian cancer stem cells unravel the mechanisms for repair and chemo-resistance," Cell Cycle, vol. 8, no. 1, pp. 158$166,2009$.

[7] Y. Luo and G. D. Prestwich, "Synthesis and selective cytotoxicity of a hyaluronic acid-antitumor bioconjugate," Bioconjugate Chemistry, vol. 10, no. 5, pp. 755-763, 1999.

[8] K. E. Miletti-González, S. Chen, N. Muthukumaran et al., "The CD44 receptor interacts with P-glycoprotein to promote cell migration and invasion in cancer," Cancer Research, vol. 65, no. 15, pp. 6660-6667, 2005.

[9] A. Giatromanolaki, E. Sivridis, A. Fiska, and M. I. Koukourakis, “The CD44+/CD24- phenotype relates to 'triple-negative' state and unfavorable prognosis in breast cancer patients," Medical Oncology, vol. 28, no. 3, pp. 745-752, 2011.

[10] H. van Epps, "Triple-negative breast cancer: divide and conquer," CURE Magazine, 2013.

[11] X. Li, M. T. Lewis, J. Huang et al., "Intrinsic resistance of tumorigenic breast cancer cells to chemotherapy," Journal of the National Cancer Institute, vol. 100, no. 9, pp. 672-679, 2008.

[12] T. Pouyani and G. D. Prestwich, "Functionalized derivatives of hyaluronic acid oligosaccharides: drug carriers and novel 
biomaterials," Bioconjugate Chemistry, vol. 5, no. 4, pp. 339-347, 1994.

[13] Y. Luo, M. R. Ziebell, and G. D. Prestwich, "A hyaluronic acid-taxol antitumor bioconjugate targeted to cancer cells," Biomacromolecules, vol. 1, no. 2, pp. 208-218, 2000.

[14] Y. Luo and G. D. Prestwich, "Synthesis and selective cytotoxicity of a hyaluronic acid-antitumor bioconjugate," Bioconjugate Chemistry, vol. 10, no. 5, pp. 755-763, 1999.

[15] M. Yu, S. Jambhrunkar, P. Thorn, J. Chen, W. Gu, and C. Yu, "Hyaluronic acid modified mesoporous silica nanoparticles for targeted drug delivery to CD44-overexpressing cancer cells," Nanoscale, vol. 5, no. 1, pp. 178-183, 2013.

[16] Z. Chen, Z. Li, Y. Lin, M. Yin, J. Ren, and X. Qu, "Biomineralization inspired surface engineering of nanocarriers for $\mathrm{pH}$ responsive, targeted drug delivery," Biomaterials, vol. 34 , no. 4 , pp. 1364-1371, 2013.

[17] M. Banik and T. Basu, "Calcium phosphate nanoparticles: a study of their synthesis, characterization and mode of interaction with salmon testis DNA," Dalton Transactions, vol. 43, no. 8, pp. 3244-3259, 2014.

[18] R. Detsch, D. Hagmeyer, M. Neumann et al., "The resorption of nanocrystalline calcium phosphates by osteoclast-like cells," Acta Biomaterialia, vol. 6, no. 8, pp. 3223-3233, 2010.

[19] V. Sokolova, O. Rotan, J. Klesing et al., "Calcium phosphate nanoparticles as versatile carrier for small and large molecules across cell membranes," Journal of Nanoparticle Research, vol. 14, article 910, 2012.

[20] J. L. Vanderhooft, M. Alcoutlabi, J. J. Magda, and G. D. Prestwich, "Rheological properties of cross-linked hyaluronangelatin hydrogels for tissue engineering," Macromolecular Bioscience, vol. 9, no. 1, pp. 20-28, 2009.

[21] X. Z. Shu, Y. Liu, and G. D. Prestwich, "Modified macromolecules and methods of making and using thereof," 7, 981, 871, 2011.

[22] W. Jiang, H. Pan, Y. Cai et al., "Atomic force microscopy reveals hydroxyapatite-citrate interfacial structure at the atomic level," Langmuir, vol. 24, no. 21, pp. 12446-12451, 2008.

[23] X. Cheng and L. Kuhn, "Chemotherapy drug delivery from calcium phosphate nanoparticles," International Journal of Nanomedicine, vol. 2, no. 4, pp. 667-674, 2007.

[24] B. Palazzo, M. Iafisco, M. Laforgia et al., "Biomimetic hydroxyapatite-drug nanocrystals as potential bone substitutes with antitumor drug delivery properties," Advanced Functional Materials, vol. 17, no. 13, pp. 2180-2188, 2007.

[25] M. Murohashi, K. Hinohara, M. Kuroda et al., "Gene set enrichment analysis provides insight into novel signalling pathways in breast cancer stem cells," British Journal of Cancer, vol. 102, no. 1, pp. 206-212, 2010.

[26] C. Sheridan, H. Kishimoto, R. K. Fuchs et al., "CD44 ${ }^{+} / \mathrm{CD} 24^{-}$ breast cancer cells exhibit enhanced invasive properties: an early step necessary for metastasis," Breast Cancer Research, vol. 8, no. 5, article R59, 2006.

[27] G. Dontu, W. M. Abdallah, J. M. Foley et al., "In vitro propagation and transcriptional profiling of human mammary stem/progenitor cells," Genes and Development, vol. 17, no. 10, pp. 1253-1270, 2003.

[28] Y. Kondaveeti, I. K. Reed, and B. A. White, "Epithelialmesenchymal transition induces similar metabolic alterations in two independent breast cancer cell lines," Cancer Letter, vol. 364, no. 1, pp. 44-58, 2015.
[29] U. Bhardwaj and D. J. Burgess, "A novel USP apparatus 4 based release testing method for dispersed systems," International Journal of Pharmaceutics, vol. 388, no. 1-2, pp. 287-294, 2010.

[30] I. K. Guttilla, K. N. Phoenix, X. Hong, J. S. Tirnauer, K. P. Claffey, and B. A. White, "Prolonged mammosphere culture of MCF-7 cells induces an EMT and repression of the estrogen receptor by microRNAs," Breast Cancer Research and Treatment, vol. 132, no. 1, pp. 75-85, 2012.

[31] R. Singh and J. W. Lillard Jr., "Nanoparticle-based targeted drug delivery," Experimental and Molecular Pathology, vol. 86, no. 3, pp. 215-223, 2009.

[32] C. Andres, V. Sinani, D. Lee, Y. Gun'ko, and N. Kotov, "Anisotropic calcium phosphate nanoparticles coated with 2carboxyethylphosphonic acid," Journal of Materials Chemistry, vol. 16, no. 40, pp. 3964-3968, 2006.

[33] A. Dosen and R. F. Giese, "Thermal decomposition of brushite, $\mathrm{CaHPO}_{4} \cdot 2 \mathrm{H}_{2} \mathrm{O}$ to monetite $\mathrm{CaHPO}_{4}$ and the formation of an amorphous phase," American Mineralogist, vol. 96, no. 2-3, pp. 368-373, 2011.

[34] P. Grodzinski and D. Farrell, "Future opportunities in cancer nanotechnology-NCI strategic workshop report," Cancer Research, vol. 74, no. 5, pp. 1307-1310, 2014.

[35] J. L. Giocondi, B. S. El-Dasher, G. H. Nancollas, and C. A. Orme, "Molecular mechanisms of crystallization impacting calcium phosphate cements," Philosophical Transactions of the Royal Society A: Mathematical, Physical and Engineering Sciences, vol. 368, no. 1917, pp. 1937-1961, 2010.

[36] Y.-Y. Hu, A. Rawal, and K. Schmidt-Rohr, "Strongly bound citrate stabilizes the apatite nanocrystals in bone," Proceedings of the National Academy of Sciences of the United States of America, vol. 107, no. 52, pp. 22425-22429, 2010.

[37] M. A. Martins, C. Santos, M. M. Almeida, and M. E. V. Costa, "Hydroxyapatite micro- and nanoparticles: nucleation and growth mechanisms in the presence of citrate species," Journal of Colloid and Interface Science, vol. 318, no. 2, pp. 210216, 2008.

[38] K. Bleek and A. Taubert, "New developments in polymercontrolled, bioinspired calcium phosphate mineralization from aqueous solution," Acta Biomaterialia, vol. 9, no. 5, pp. 62836321, 2013.

[39] G. D. Prestwich, "Clinical biomaterials for scar-free healing and localized delivery of cells and growth factors," Advances in Wound Care, vol. 1, pp. 394-399, 2010.

[40] G. D. Prestwich, "Hyaluronic acid-based clinical biomaterials derived for cell and molecule delivery in regenerative medicine," Journal of Controlled Release, vol. 155, no. 2, pp. 193-199, 2011.

[41] G. D. Prestwich, I. E. Erickson, T. I. Zarembinski, M. West, and W. P. Tew, "The translational imperative: making cell therapy simple and effective," Acta Biomaterialia, vol. 8, no. 12, pp. 42004207, 2012.

[42] C. Tassa, J. L. Duffner, T. A. Lewis et al., "Binding affinity and kinetic analysis of targeted small molecule-modified nanoparticles," Bioconjugate Chemistry, vol. 21, no. 1, pp. 14-19, 2010.

[43] J. Lesley, V. C. Hascall, M. Tammi, and R. Hyman, "Hyaluronan binding by cell surface CD44," The Journal of Biological Chemistry, vol. 275, no. 35, pp. 26967-26975, 2000.

[44] M. Al-Hajj, M. S. Wicha, A. Benito-Hernandez, S. J. Morrison, and M. F. Clarke, "Prospective identification of tumorigenic breast cancer cells," Proceedings of the National Academy of Sciences of the United States of America, vol. 100, no. 7, pp. 39833988, 2003. 
[45] H. S. S. Qhattal and X. Liu, "Characterization of CD44mediated cancer cell uptake and intracellular distribution of hyaluronan-grafted liposomes," Molecular Pharmaceutics, vol. 8, no. 4, pp. 1233-1246, 2011.

[46] S. Kumar, X. Xu, R. Gokhale, and D. J. Burgess, "Formulation parameters of crystalline nanosuspensions on spray drying processing: a DoE approach," International Journal of Pharmaceutics, vol. 464, no. 1-2, pp. 34-45, 2014.

[47] V. Sokolova and M. Epple, "Inorganic nanoparticles as carriers of nucleic acids into cells," Angewandte Chemie-International Edition, vol. 47, no. 8, pp. 1382-1395, 2008.

[48] E. R. Jamieson and S. J. Lippard, "Structure, recognition, and processing of cisplatin-DNA adducts," Chemical Reviews, vol. 99, no. 9, pp. 2467-2498, 1999.

[49] D. P. Silver, A. L. Richardson, A. C. Eklund et al., "Efficacy of neoadjuvant cisplatin in triple-negative breast cancer," Journal of Clinical Oncology, vol. 28, no. 7, pp. 1145-1153, 2010. 

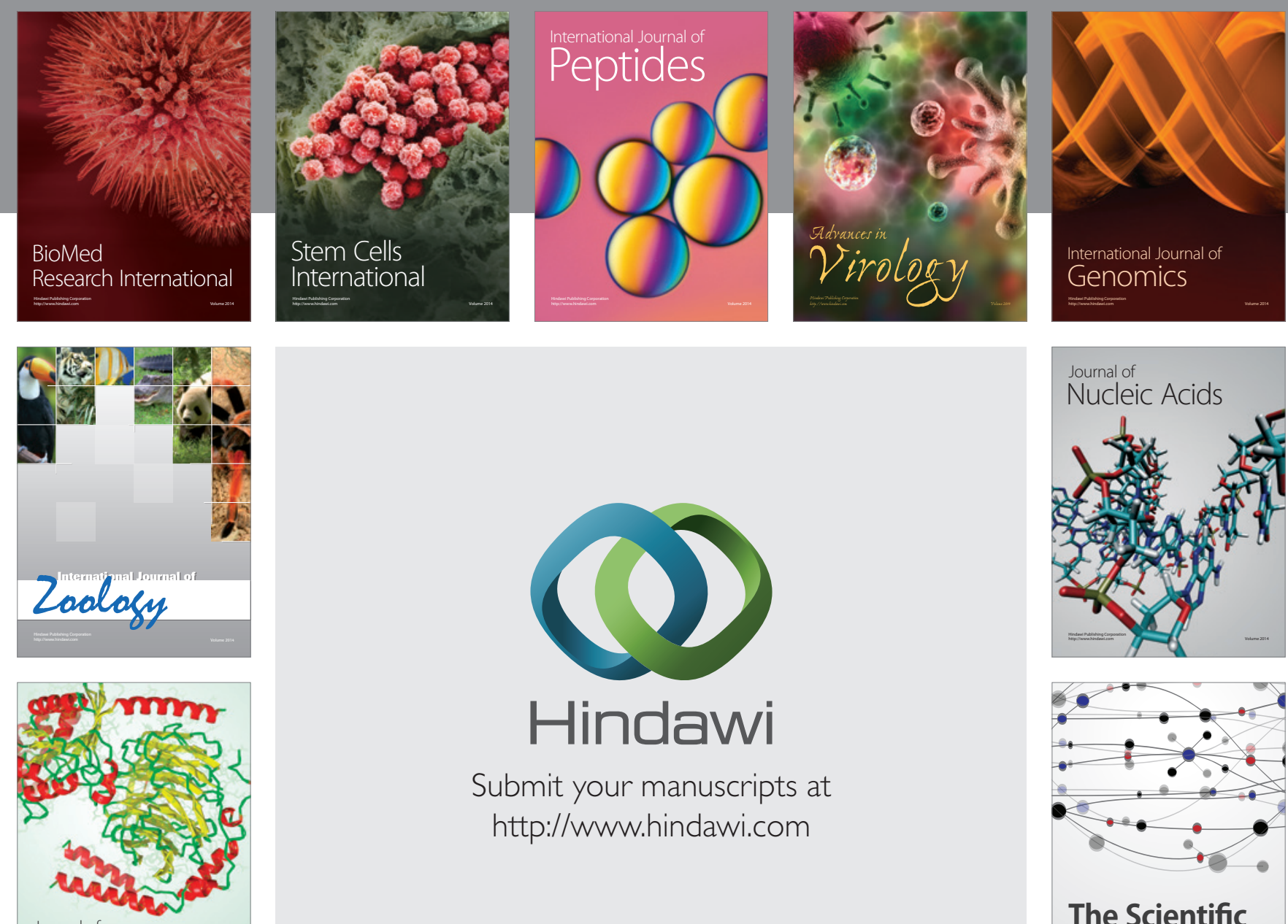

Submit your manuscripts at

http://www.hindawi.com

Journal of
Signal Transduction
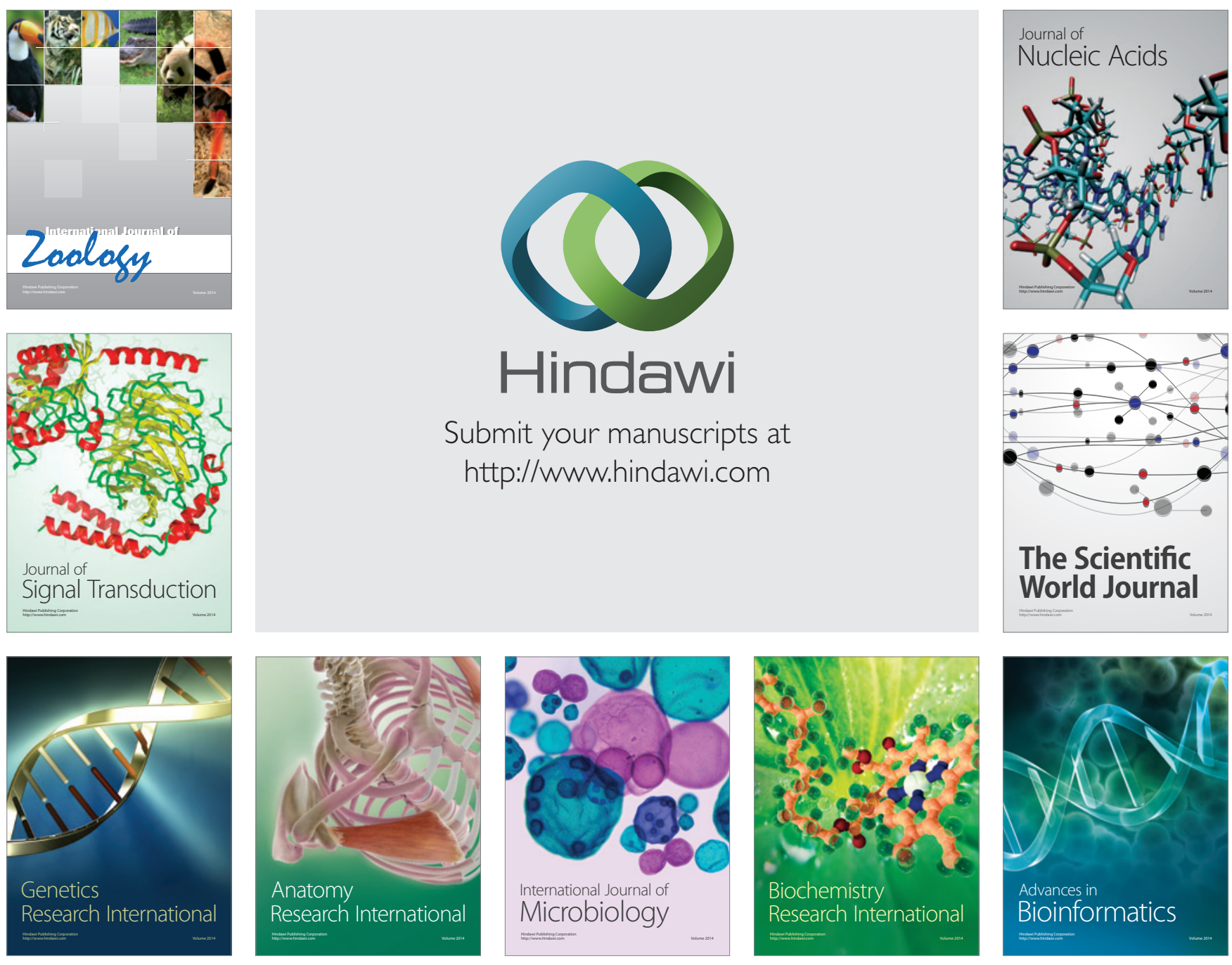

The Scientific World Journal
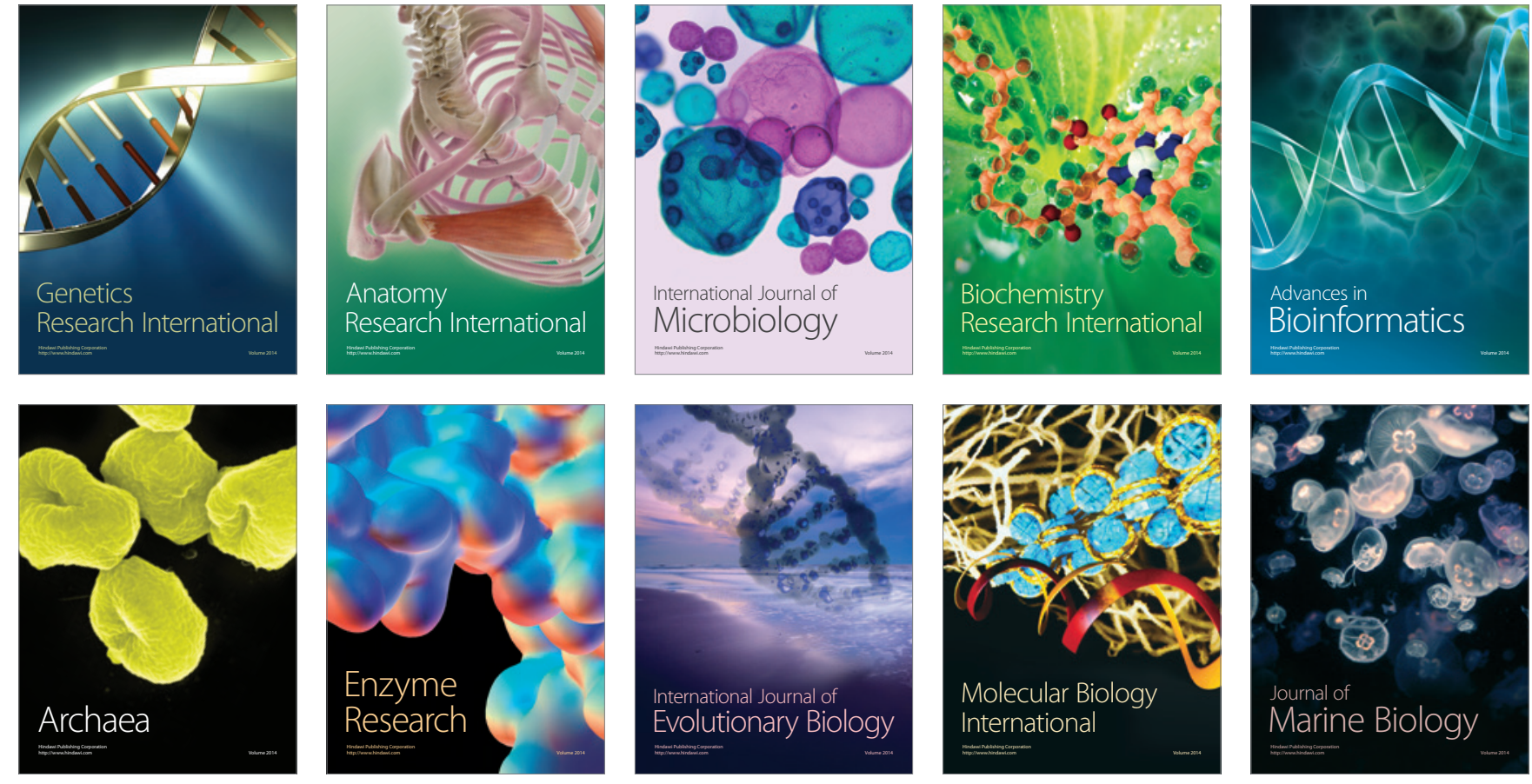